\title{
Microstructure and Mechanical Properties Investigation of Ni35A-TiC Composite Coating Deposited on AISI 1045 Steel by Laser Cladding
}

\section{Hao Zhang}

Wuhan University of Science andTechnology

\section{Guofu Lian}

Fujian University of Technology

\section{Qiang Cao}

Fujian University of Technology

\section{Yingjun Pan}

Wuhan University of Science andTechnology

\section{Yang Zhang ( $\nabla$ yzhang@wcu.edu )}

Western Carolina University https://orcid.org/0000-0001-8810-2770

\section{Research Article}

Keywords: Laser cladding, Composite coating, Microstructure, Micro-hardness, Wear resistance

Posted Date: July 16th, 2021

DOl: https://doi.org/10.21203/rs.3.rs-702108/v1

License: (9) This work is licensed under a Creative Commons Attribution 4.0 International License. Read Full License

Version of Record: A version of this preprint was published at The International Journal of Advanced Manufacturing Technology on September 15th, 2021. See the published version at https://doi.org/10.1007/s00170-021-08011-4. 


\section{Abstract}

In this research, the TiC-Ni35A composite coating was fabricated on the AISI 1045 steel substrate by laser cladding process. The cross-sectional morphology, microstructure, micro-hardness, and wear resistance of coatings obtained under different laser energy densities (E) and TiC powder ratios (PR) were analyzed. According to the results, all the coating had a reliable metallurgical bonding with the AISI 1045 steel substrate. The X-ray diffraction (XRD) analysis revealed that the coating phases were Ni and TiC. The average microhardness of the Ni35A-80wt.\% TiC coating reached up to $75.12 \mathrm{HRC}$. The minimum coefficient of friction of the composite coating was only about $30 \%$ of the AISI 1045 substrate. The wear form was mainly adhesive wear when altering the TiC powder ratios, while the wear form also contained abrasion wear under different energy densities. The ability of decomposition and re-nucleation of TiC was significantly improved with the increase of laser energy densities and the decrease of TiC powder ratios. The micro-hardness, wear resistance, and coefficient of friction of the composite coating were improved because of the TiC strengthening phase particles. Compared with the AISI 1045 steel substrate, the microhardness and wear resistance of the composite coating was increased by 5.29 times and 6.26 times, respectively.

\section{Introduction}

Surface treatment has been a concentration received extensively study as a key technology for the repair and remanufacturing of industrial parts. The surface treatment can reduce material waste effectively and prepare components according to the performance requirements of special parts. There are varies types of surface treatment techniques, such as Physical Vapor Deposition (PVD), Chemical Vapor Deposition (CVD), Thermal Spraying, and Laser Surface Treatment[1]. As one of the advanced laser surface treatment technologies, laser cladding utilizes a high-energy-density laser beam as the energy source to melt the alloy powder and part of the substrate at the same time[2, 3]. The alloy powder is delivered into the molten pool by either synchronous feeding or preseting to form a reliable metallurgical bonding between the substrate and coating. Because of the simple process, superior processing efficiency, rapid heating and rapid cooling $\left(10^{5}-10^{8} \mathrm{~K} / \mathrm{s}\right)$, low coating dilution rate, and small deformation, laser cladding uses the shortest cycle to achieve the purpose of surface modification and repair[4-8]. At present, it has been widely utilized in the repair and remanufacturing of high-value parts or parts with distinctive shapes $[9,10]$.

Since the properties of the cladding layer mainly determined by the coating material, a considerable amount of scholars utilized different materials to obtain cladding layers, and the most typical of which is self-fluxing alloys. According to its core elemental content, it is classified as iron-based, nickel-based, cobalt-based, and other self-fluxing alloys[11, 12]. Since nickel-based alloys have good wettability, corrosion resistance, oxidation resistance, fatigue resistance, impact resistance, and other remarkable properties in high-temperature environments, they have been widely applied in cold metalwork parts, crushing rollers, shafts, and other mechanical parts manufacturing[13-15]. However, its low wearresistance and poor hardness of nickel-based alloys lead to a shortened service life and a limitation in the 
application range[16]. In order to improve the hardness and wear resistance of the nickel-based alloy, the typical method is to add ceramic/hard phase particles to the nickel-based alloy[17, 18]. Metal matrix composites coatings (MMCs) are widely used in surface protection due to their extreme hardness, high fatigue strength, and superior wear resistance. As a typical reinforcement material, TiC was often selected as a "second phase" reinforcement particle added to the metal material due to its high melting point ( $\left.3000^{\circ} \mathrm{C}\right)$, high hardness $(2800-3200 \mathrm{HV})$, low friction coefficient, high elastic modulus, and low density $(\sim$ $4.93 \mathrm{~g} / \mathrm{cm}^{3}$ ). Also, the ductility of titanium carbide can be increased with nickel to prepare highperformance coatings because of the good wettability between $\mathrm{Ni}$ and TiC[19-22]. Hu et al. [23] obtained $\mathrm{NiCrCoMo/TiC} \mathrm{composite} \mathrm{coatings} \mathrm{by} \mathrm{plasma} \mathrm{sprayed} \mathrm{using} \mathrm{NiCrCoMo} \mathrm{alloy} \mathrm{powders} \mathrm{and} \mathrm{Ti}-\mathrm{C}$ powders. According to their results, with the increase of Ti-C powder content, the average porosity and hardness of the coating increased, and the wear volume decreased significantly. Saroj et al. [24] analyzed TiC-Inconel825 composite coating deposited on AISI 304 steel by tungsten inert gas (TIG) process, the micro-hardness increased with the increase of TiC content and the decrease of the current, the wear resistance was enhanced 7 times after coating compared with the substrate. Saeedi et al.[25] investigated the hardness and mass loss of the NiCr-TiC composite clad. They found that the hardness increased and mass loss decreased with adding reinforcement particles, the mass loss for NiCr-TiC was almost three times less than that of the stainless steel substrate without cladding. Gu et al.[26] investigated densification, microstructure, and mechanical properties of nano-TiC reinforced Inconel 718 composites processed by selective laser melting (SLM) with the variation of laser energy linear density (E). A high nano-hardness, low friction coefficient, and low wear rate can be obtained when the $E$ was 300 $\mathrm{J} / \mathrm{m}$, showing a significantly improved mechanical performance compared to the SLM-processed unreinforced nickel-based alloys. Many researchers have conducted sufficient research on additional effects of nickel-based alloys-TiC composite coatings[27-31].

However, there are few reports on composite coatings that fully consider the combined effect of laser cladding process parameters. Moreover, the type and content of different strengthening phase has different energy requirements and which has an important influence on the forming quality of the coating. Therefore, in the presented work, laser cladding was used to obtain TiC reinforced Ni35A composite coating on the AISI 1045 steel substrate to improve the mechanical properties (e.g. microhardness, wear resistance) and forming quality. The effect of laser energy density and TiC powder ratio on the cross-sectional morphology, microstructure, microhardness and wear resistance of the coating have been extensively investigated. The results can guide the improvement of mechanical properties and forming quality in the composite material surface coating process.

\section{Material And Methods}

At first, the AISI 1045 steel was selected as the substrate with a size of $40 \mathrm{~mm} \times 20 \mathrm{~mm} \times 5 \mathrm{~mm}$. The laser beam diameter was adjusted to $4 \mathrm{~mm}$. Cladding powder was made from Ni35A and TiC powder (Chengdu HUAYIN powder technology co., Ltd., Chengdu China) with a particle size ranging from $48 \mu \mathrm{m}$ to $106 \mu \mathrm{m}$. The elemental composition of Ni35A and TiC powder are shown in Table 1. Fig. 1 shows the 
scanning electron microscopy (SEM) image of the Ni35A powder, TiC powder, and TiC/Ni35A powder after ball milling.

Table.1 Elemental composition (wt.\%) of Ni35A and TiC powder.

\begin{tabular}{|c|c|c|c|c|c|c|c|c|c|c|}
\hline \multirow[t]{2}{*}{ Powder } & \multicolumn{10}{|c|}{ Element (wt.\%) } \\
\hline & C & Si & 0 & $\mathrm{Fe}$ & $\mathrm{Cr}$ & B & T.C & F.C & $\mathrm{N}$ & $\mathrm{Ni}$ \\
\hline $\mathrm{Ni35A}$ & 0.32 & 3.35 & $<0.05$ & 2.75 & 7.75 & 1.65 & - & - & - & Rest \\
\hline $\mathrm{TiC}$ & - & 0.02 & 0.5 & 0.08 & - & - & $>18.8$ & $<0.5$ & 0.5 & - \\
\hline
\end{tabular}

Fig.2 shows the laser cladding system and laser cladding process. The laser cladding system includes a laser system (YLS-3000, IPG, Burbach, Germany), laser cladding nozzle with $300 \mathrm{~mm}$ focal length (FDH0273, Lasermech, Novi, MI, USA), industrial robot (M-710iC/50, FANUC, Yamanashi, Japan), water cooling system (TFLW-4000WDR-01-3385, Sanhe Tongfei, Sanhe, China), powder feeding system (CRPGF-D-2, Songxing, Fuzhou,Changhua County,China), control system (PLC, Mitsubishi, Japan), and laser pulse control system (SX14-012PULSE, IPG, Burbach, Germany). Argon gas was used as carrier and protective gas during the laser cladding process.

Before cladding, the AISI 1045 steel substrate surface was cleaned with ethanol. The Ni35A and TiC powder was mixed in a MITR--YXQM-2L ball mill machine (MITR, Changsha, China) for $30 \mathrm{~min}$ at a speed of $300 \mathrm{rpm}$ and then placed in a vacuum dryer for an additional $30 \mathrm{~min}$ at a temperature of $120^{\circ} \mathrm{C}$. After completion of the laser cladding, the sample was processed by cutting, setting, grinding, and polishing. Then the sample was immersed in 4\% nitric acid and alcohol mixture for 3s. An MVA-402TS microhardness tester (HDNS, Shanghai, China) was utilized to measure the micro-hardness with a 500 gramforce applied for a 30-second duration. The microstructure was observed using a scanning electron microscope (SEM) TM3030Plus (HITACHI 550I, Tokyo, Japan). In addition, element analysis was performed using an energy-dispersive X-ray spectroscopy (EDS) system (A550I, IXRF, Austin, TX , USA). The wear resistance was examined with a UMT-2 high load scratch tester (Bruker, Billerica, MA, USA). The X-ray diffraction (XRD) analysis was conducted with Ultima IV XRD systems (Rigaku Corporation, Tokyo, Japan) at a scanning speed of $4^{\circ} / \mathrm{min}$ and scanning angle range from $20^{\circ}$ to $80^{\circ}$. 3D morphology of the abrasion surface was obtained using white light interferometry. In addition, a vernier caliper with an accuracy of $0.01 \mathrm{~mm}$ was used to measure the wear height loss of the coating after the scratch test, and the average value was calculated for 3 measurements. Conditions for the wear test are shown below in Table 2.

Table.2 Scratch testing parameters. 


\begin{tabular}{lll} 
Parameters & Unit & Specifications \\
\hline Friction pair & - & Cemented Carbide- $\$ 6 \mathrm{~mm}$ \\
\hline Force & $\mathrm{N}$ & 35 \\
\hline Speed & $\mathrm{mm} \cdot \mathrm{s}^{-1}$ & 10 \\
\hline Distance & $\mathrm{mm}$ & 4 \\
\hline Duration & $\mathrm{min}$ & 60 \\
\hline Mode & - & Reciprocating \\
\hline Temperature & ${ }^{\circ} \mathrm{C}$ & Room temperature
\end{tabular}

The laser cladding processing parameter variables were exhibited in Table 3. The influence of TiC powder ratio $(\mathrm{PR})$ on the forming quality and performance of composite coating were investigated by preparing five different types of samples with different TiC powder ratios on the AISI 1045 steel substrate.

Note that during the laser cladding process, the forming quality and performance of coating influenced by laser power, scanning speed, laser beam diameter et al. Therefore, this paper also investigated the specific energy density (E) supplied to the melt pool, which was calculated using the follow equation $1[32$, 33]:

$$
\mathrm{E}=\left[\mathrm{P} /\left(\pi \mathrm{r}^{2}\right)\right](2 \mathrm{r} / \mathrm{v})
$$

Where $P$ is the laser power $(w), r$ is the laser spot radius $(\mathrm{mm}), v$ is the laser scanning speed $\left(\mathrm{mm} \cdot \mathrm{s}^{-1}\right)$, and $(2 \mathrm{r} / \mathrm{v})$ is the laser-material interaction time.

Based on the properties of TiC and the analysis of the coating at different TiC powder ratios, although higher TiC powder ratio can improve the micro-hardness and wear resistance of the coating, cracks were easily generated in the coating due to the brittleness of $\mathrm{TiC}$, which can further promote the peeling off phenomenon of the coating (see Fig.3(e)). Besides, the decomposition and re-nucleation of TiC was best when the TiC powder ratio was $40 \mathrm{wt} . \%$. In addition, the deposited coating exhibited a reliable bonding with the substrate according to the results of the coating morphology and microstructure. Therefore, 40 wt.\% TiC powder ratio was selected to further the investigation by altering the energy density. The energy

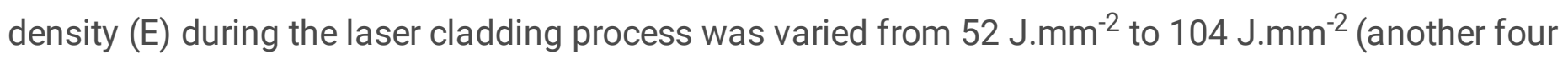
samples in Table 3).

Table.3 Experimental design for composite coating. 


\begin{tabular}{llllll} 
Sample & Laser power & Scanning speed & Gas flow & TiC powder ratio & Energy Density \\
& $/(\mathrm{w})$ & $/\left(\mathrm{mm}^{-1}\right)$ & $/\left(\mathrm{L} \cdot \mathrm{h}^{-1}\right)$ & $/(\mathrm{wt} . \%)$ & $/\left(\mathrm{J} \cdot \mathrm{mm}^{-2}\right)$ \\
\hline 1 & 1300 & 6 & 1200 & 0 & 69 \\
\hline 2 & 1300 & 6 & 1200 & 20 & 69 \\
\hline 3 & 1300 & 6 & 1200 & 40 & 69 \\
\hline 4 & 1300 & 6 & 1200 & 60 & 69 \\
\hline 5 & 1300 & 6 & 1200 & 80 & 69 \\
\hline 6 & 1300 & 8 & 1200 & 40 & 52 \\
\hline 7 & 1100 & 6 & 1200 & 40 & 58 \\
\hline 8 & 1500 & 6 & 1200 & 40 & 80 \\
\hline 9 & 1300 & 4 & 1200 & 40 & 104
\end{tabular}

\section{Results And Discussion}

\subsection{Coating morphology}

Fig.3 illustrates the cross-sectional SEM images of a typical single track coating by laser cladding process with $69 \mathrm{~J} . \mathrm{mm}^{-2}$ energy density for different TiC contents $(0,20,40,60,80 \mathrm{wt}$.\%). Generally, all the coating had the excellent bonded interfaces with the substrate. It can be observed that coating was composed of four zones, including cladding zone (CZ), bonding zone (BZ), heated affected zone (HAZ) and substrate (SZ).

It can be noted that the coating of Fig.3(a) had no dark phase, and the forming quality was greater than others. In addition, it was evident that Fig.3(b-e) had an almost uniform composite coating without obvious structural difference. However, it can be found that when the TiC content was 80 wt.\%(Fig.3(e)), obvious cracks and peeling off phenomenon were observed in the coating. This was caused by the excessive TiC powder ratio, leading to the increase of the brittleness of the cladding layer and increasing the tendency to generate the cracks. Due to the high melting point of TiC, when TiC powder content kept increased to $80 \mathrm{wt}$.\% in the powder mixture, the thermal energy of laser was primarily absorbed by TiC. Consequently, the laser energy absorbed by the molten pool under this condition was relatively lower than other samples with lower TiC percentages. As a result, with the increase of the solidification rate in the molten pool, and the residual stress in the coating was unable to release and form cracks[34]. In addition, the excessive TiC content in the powder mixture was not able to fully reach the decomposition and renucleation temperature[35, 36], which lead to the TiC only adhering to the surface of the cladding layer, and accelerating its tendency to peel off from the coating. 
Fig.4 and Fig.3(c) illustrate the cross-sectional SEM images of TiC-Ni35A composite coating deposited by laser cladding process with 40wt.\% TiC content at different energy densities $\left(52,58,69,80,104 \mathrm{~J} . \mathrm{mm}^{-2}\right)$. It can be seen that the coatings had no interfacial gap appeared between the cladding layer and substrate at different energy densities. Moreover, it can be found that large TiC particles existed in the cladding layer when laser energy density was $52 \mathrm{~J} . \mathrm{mm}^{-2}$, while small TiC particles were observed when laser energy density was $104 \mathrm{~J} . \mathrm{mm}^{-2}$. The lifetime of the molten pool was extended with the increase of laser energy density, which resulted in a significant increase in the convection effect of the molten pool[37]. Hence, the TiC powder in the cladding layer had more time to decompose and re-nucleate, resulting in fine TiC particles.

\subsection{XRD analysis}

Fig. 5 shows the X-ray diffraction (XRD) patterns of TiC-Ni35A composite coating on the AISI 1045 steel with different TiC powder ratios $(0,20,40,60,80 \mathrm{wt} . \%)$ by laser cladding process. The analysis by XRD was performed in order to identify the type of component phase in the coating. It can be noted that the TiC-Ni35A composite coating layer was mainly composed of $\mathrm{TiC}$ and $\mathrm{Ni}$, and it can be demonstrated that no new secondary phases were formed other than $\mathrm{TiC}$ and Ni during the laser cladding process, since the laser cladding process of the research was mainly a physical reaction and chemical was negligible. No significant differences in the XRD patterns was observed when TiC was added to the sample and there was merely a difference in the peak intensities due to the difference in TiC content percentage . Interestingly, it can be found that the relative intensity of TiC peak reached a maximum in $80 \mathrm{wt} . \% \mathrm{TiC}$ (sample 5) at $2 \theta$ position of 41.48 degree, and the relative intensity of Ni peak reached a maximum in Owt.\% TiC(sample 1 ) at $2 \theta$ position of 43.98 degree.

\subsection{Microstructure}

It is well known that the microstructure of any coating had a significant impact on its properties. Therefore, detailed microstructural analysis study of produced coatings is indispensable to evaluate its mechanical performance(e.g. micro-hardness, wear resistance). In this study, the microstructure of the cladding layer was investigated to comprehend the effect of the TiC powder ratio and the energy density in the laser cladding process.

Fig. 6 shows the microstructure approximately in the middle region in the cladding zone of the laser cladding processed composite coating with the varies $\operatorname{TiC}$ powder ratio $(0,20,40,60,80 \mathrm{wt} . \%)$. It is clearly to be found that SEM images (Fig.6) show a significant difference with the increase of TiC content in the composite coating. The main factor of this phenomenon is that the melting temperature of TiC $\left(\sim 3000{ }^{\circ} \mathrm{C}\right)$ is considerably higher than the $\mathrm{Ni35 \textrm {A }}\left(\sim 1050^{\circ} \mathrm{C}\right)$, a higher ratio of $\mathrm{TiC}$ powder requires more energy to accomplish decomposition and re-nucleation process.

The EDS analysis in the whole area corresponding to Fig. 6 was performed and the results were illustrated in Table.4. It can be found that in the row of Fig.6(a) the elemental composition was similar to the Ni35A powder in the coating prepared without any TiC powder. Interestingly, the $\mathrm{C}$ and Ti percentage in the 
cladding layer increased gradually with the increase of TiC powder ratio (Fig.6(b)- Fig.6(e)), it is evident that the total content of $\mathrm{Ti}$ and $\mathrm{C}$ was almost equal to $\mathrm{TiC}$ powder ratio. In contrast, the percentage of $\mathrm{Cr}$, $\mathrm{Fe}, \mathrm{Ni}$ decreased with the increase of $\mathrm{TiC}$ powder ratio in the coating.

In general, the microstructure had no secondary dendrite arm in the SEM image as shown in Fig.6(a).

Fig.6(b) to 6(e) display the microstructure of TiC changed from the dendritic crystal structure to larger TiC paricle structure. This phenomenon was formed by the TiC content in these four different set of TiC powder ratio $\left(20,40,60,80 \mathrm{wt}\right.$.\%). Since the laser energy density was kept at $69 \mathrm{~J} . \mathrm{mm}^{-2}$ for all the setpoint and the melting temperature of $\mathrm{TiC}$ is reasonably higher than the melting temperature of Ni35A, the melting of TiC powder became less incomplete when adding more TiC content. With the increased amount of TiC percentage from 20 wt.\% in Fig.6(b) to 80 wt.\% in Fig. 6(e), the trend of decomposition and re-nucleation of the dissolved TiC grow into the dendritic crystal structure became weakened and resulted large TiC particle structure. Note that Fig.6(e) shows that the corners and sharp edges of the TiC particles had a slight smoothness[36, 38], with respect to their original morphology as a reinforcing phase within a very fewer amount Ni35A in the coating.

In order to identify the different shaded regions (dark and light) in the coating morphology, high magnified SEM image and corresponding EDS analysis were performed for the coating produced with 40wt.\% [Fig.6(c),(marked 1, 2)] as demonstrated in Fig.7. Elemental analysis by EDS corresponding to the dark and light region was tabulated in Table.5. It can be noticed that the dark region (marked as 1) was composed of high percentage of $\mathrm{Ti}$ and $\mathrm{C}$. Contrastly, the light region (marked as 2 ) had a high elemental content of $\mathrm{Cr}, \mathrm{Fe}, \mathrm{Ni}$ in combination with less amount of $\mathrm{Ti}$ and $\mathrm{C}$. Considering the XRD analysis results, it can be determined that the dark region and light region was $\mathrm{TiC}$ and Ni-based alloy, respectively.

Table.4 EDS analysis corresponding to SEM images in Fig.6.

\begin{tabular}{llllll} 
Sample & \multicolumn{5}{l}{ Element(wt.\%) } \\
\cline { 2 - 6 } & $\mathrm{C}$ & $\mathrm{Ti}$ & $\mathrm{Cr}$ & $\mathrm{Fe}$ & $\mathrm{Ni}$ \\
\hline Fig.6(a) & 1.403 & 0.158 & 6.241 & 3.415 & 88.783 \\
\hline Fig.6(b) & 3.781 & 16.342 & 5.004 & 2.070 & 72.804 \\
\hline Fig.6(c) & 5.860 & 35.145 & - & 3.187 & 55.808 \\
\hline Fig.6(d) & 7.629 & 51.846 & - & 1.406 & 39.119 \\
\hline Fig.6(e) & 12.369 & 83.807 & - & 1.259 & 2.566
\end{tabular}

Table.5 EDS analysis corresponding to SEM image of Fig.6(c) 


\begin{tabular}{llllll} 
Spectrum & \multicolumn{4}{l}{ Element(wt.\%) } \\
\cline { 2 - 6 } & $\mathrm{C}$ & $\mathrm{Ti}$ & $\mathrm{Cr}$ & $\mathrm{Fe}$ & $\mathrm{Ni}$ \\
\hline Dark region(\#1) & 10.318 & 76.954 & - & 0.754 & 11.974 \\
\hline Light region(\#2) & 4.436 & 11.577 & 4.518 & 2.285 & 77.184
\end{tabular}

Fig.8 illustrates the SEM images of the composite coating produced with $40 \mathrm{wt} . \% \mathrm{TiC}$ at different laser energy densities ( $52,58,80,104 \mathrm{~J} . \mathrm{mm}^{-2}$ ), where Fig.6(c) shows the microstructure at the laser energy at $69 \mathrm{J.mm}^{-2}$. It can be clearly seen from the Fig.8 and Fig.6(c) that when the TiC powder ratio was fixed, the morphology of the TiC in the composite coating hardly changed with the increase of the laser energy density. However, the ability of decomposition and re-nucleation of TiC particles were significantly influenced by different energy densities. The TiC particles became smaller as the laser energy density increased. It can be concluded that the TiC particles can absorb more energy for decomposition and renucleation at the same time as the increase of laser energy density, and which obtained a finer and uniform microstructure [39]. Besides, due to the TiC powder ratio in the composite coating was fixed at this condition, the energy required for the decomposition and re-nucleation of $\mathrm{TiC}$ was constant, so the excessive energy will no longer be used for decomposition and re-nucleation. When the laser energy density reached a certain limit, the size of TiC particles tended to be stablizaed, see Fig. 8(c) and Fig.8(d).

Fig. 9 illustrates the mapping EDS analysis of the cross-section of the coating produced with $58 \mathrm{~J} . \mathrm{mm}^{-2}$ energy density and $40 \mathrm{wt} . \% \mathrm{TiC}$. It can be found that the dark phase in the coating was rich in $\mathrm{C}$ and $\mathrm{Ti}$, while the light phase was composed of a large amount of $\mathrm{Ni}$. It can be determined that the dark phase was $\mathrm{TiC}$ and the light phase was $\mathrm{Ni}$, which was consistent with the results presented in Fig.6, Fig.7, Table 4 , and XRD phase analysis. In addition, a small amount of $\mathrm{Fe}$ and $\mathrm{Cr}$ can be discovered in the coating. Under the action of a high-energy laser beam, the Fe and Cr elements in the AISI 1045 steel substrate entered into the coating under the convection in the molten pool during the cladding process.

\subsection{Microhardness}

To investigate the micro-hardness of the produced TiC-Ni35A composite coating and its variation with the position of the coating, micro-hardness was measured at the cross-section of the composite coating. Figs.10-11 represent the micro-hardness profile measured against the position of the composite coating from the top surface of coating to the substrate for samples processed at different conditions.

Fig.10 shows the micro-hardness profile of the composite coating measured at multiple positions with different TiC powder ratios. It can be observed a sharp increase trend in the micro-hardness from the substrate toward the cladding layer surfaces. From the plot, the micro-hardness of composite was enhanced with the increase of TiC powder ratio. In terms of the coating zone, which refers to the first five red dots from the right side of the position axis, the average micro-hardness value ranged from $44.5 \mathrm{HRC}$ in the pure Ni35A coating to an average value of $75.12 \mathrm{HRC}$ of Ni35A-80wt.\%TiC composite coating. The micro-hardness of the coating prepared by laser cladding was significantly higher than the AISI 1045 
steel substrate, referring to the left side of the position axis. The highest micro-hardness of the coating reached nearly 5 times than that of the AISI 1045 steel substrate.

The micro-hardness increased as the increase of the TiC powder ratio because $\mathrm{TiC}$ is well known to serve as a hardness reinforment compound. When the TiC powder ratio was lower, the TiC concentration in the coating was relatively low, and the hard phase structure was correspondingly less, which was not conducive to improving the micro-hardness of the coating. On the contrary, TiC powder ratio in the coating increased gradually, which can increase the micro-hardness of the coating effectively[35].

Similarly, in order to analyze the impact of different energy density at the cross-section of the composite coating. The micro-hardness value was measured for the composite coating produced when the TiC powder ratio was $40 \mathrm{wt}$ \%. Fig. 11 shows the effect of energy density on the micro-hardness and its distribution of the composite coating. The micro-hardness value of composite coating was in the range of 50 HRC- 65 HRC. All of the composite coatings had a higher average micro-hardness value than that of the AISI 1045 steel substrate.

From the plot, the micro-hardness of the composite coating increased as the increase of energy density. Based on Fig.11, the influence of changing laser energy density did not imply obvious change on the micro-hardness of the coating, and the micro-hardness change trend was relatively gentle. It is well known that the amount, size, and distribution of strengthening particles, as well as defects of pores and micro-cracks are the main influencing factors on the micro-hardness[40, 41]. In addition, the laser power together with scanning speed determined the amount of energy density induced for all TiC particles decomposition and re-nucleation. Therefore, the increased energy density resulted in more energy during the laser cladding process, indicating that the ablitity of decomposition and re-nucleation increased effectively of TiC particles. Thus, the TiC particles had enough time to accomplish decomposition and renucleation to become smaller in their size as the increase of energy density. According to the Hall-Petch relationship, the smaller the strengthening particles, the larger the micro-hardness. In addition, the life of the molten pool was extended as the increase of the laser energy density, which resulted in a decrease in the solidification rate of the molten pool, and TiC particles had sufficient time to decompose and renucleate. The prolonged lifespan of the molten pool was beneficial to the release of residual stress in the coating and increased the path of pores to escape from the coating, etc. Hence, it is possible to reduce the defects and increase the micro-hardness of the coating. Under the action of high energy density, the iron element in the AISI 1045 steel substrate entered into the coating through the strong convection of the molten pool to produce solid solution strengthening effect, which resulted in the coating had a greater micro-hardness with higher energy density.

\subsection{Wear resistance}

In order to analyze the wear resistance of the composite coating prepared by laser cladding, the UMT-2 high load scratch tester (Bruker, Billerica, MA, USA) was used to conduct the test of the composite coating with the friction and wear parameters shown in Table 2. The wear height loss measured under different TiC contents and different energy densities is shown in Fig.12 and Fig.13, respectively. It can be clearly 
seen from Fig.12 that the wear height loss of the composite coating became less with the increase of the TiC powder ratio (ranging from 0 to $60 \mathrm{wt} . \%$ ). However, when the TiC powder ratio reached $80 \mathrm{wt} . \%$, the wear height loss of the composite coating had a slightly increase. Owing to the coating had begin to appear the peeling off phenomenon when the TiC powder ratio reached to $80 \mathrm{wt}$.\% (see Fig.3). Meanwhile, Fig.6(e) clearly shows that a weak ability of decomposition and re-nucleation at $80 \mathrm{wt}$ \% TiC. As a result, under high-speed wear conditions, the hard phase particles were easily separated from the coating and formed wear debris. The wear debris staying on the worn surface accelerated the wear of the cladding layer, which led to the increase of the wear height loss of the coating. The minimum wear height loss of the composite coating was only $15.0 \%$ of the substrate. The results proved that the wear resistance of the coating obtained by laser cladding technology had been significantly improved compared with uncoated AISI 1045 steel substrate.

Fig.13 shows that the 3D wear morphologies of coating at different TiC powder ratios. It is evident that the wear residual in Fig.13(a)-(d) appeared less and less affected under the wear condition, which was contributed from the increasing TiC powder ratio from 0 to $60 \mathrm{wt}$.\%. When the TiC powder ratio further increased to $80 \mathrm{wt} . \%$ (Fig.13(e)), the worn surface of the coating became worse than that of $60 \mathrm{wt} . \% \mathrm{TiC}$ (Fig.13(d)). The worn surface tracks width of the coating was the largest and the worn depth was the deepest (Fig.13(a)), and there was no accumulation of wear debris in the worn coating, indicating that the wear of the coating was more serious. When the TiC powder ratio was 20wt.\% (Fig.13(b)), the worn track in the coating became narrower compared with Fig.13(a), and a large amount of wear debris was found to accumulate. The type of wear debris was mostly formed by the composite coating peeling off under high-speed friction and the wear form of the cladding layer was adhesive wear. Besides, the TiC hard phase particles acted as an anti-wear skeleton in the coating. However, due to the low TiC powder ratio in the cladding layer, the effect of anti-wear skeleton decreased at this condition, which resulted in wear debris on the worn surface. Hence, the peeled-off hard phase particles continued to act as abrasive particles in the dry friction process until it disappeared on the worn surface, and the cladding layer had a wider and deeper worn track. With the TiC content increased to $40 \mathrm{wt} . \%$ and $60 \mathrm{wt} . \%$, the worn track became shallower and narrower. More reinforcement phases can prevent the coating from forming wear debris during the wear process to reduce wear. Interestingly, when the TiC powder was increased to $80 \mathrm{wt} . \%$, the worn surface track of the coating became deeper in the comparison with that of $60 \mathrm{wt} . \% \mathrm{TiC}$. According to the analysis of the cross-sectional morphology in Fig.3, it is shown that the TiC hard phase particles cannot be fully completed the process of decomposition and re-nucleation under a certain energy density ( $69 \mathrm{~J} . \mathrm{mm}^{-2}$ ). Hence, a large amount of TiC hard particles were not able to dissolve into the Ni35A phase, which were adhered to the surface and had poor bonding with the coating. During the highspeed wear, these TiC particles were peeling off easily and led to a worse surface morphology in the worn track than that of $60 \mathrm{wt} . \%$. In summary, all analysis of worn surface morphology was consistent with the analysis trend of wear height loss, and the wear form of the Ni35A/TiC composite coating was primarily adhesive wear. 
Fig.14 illustrates the different wear height loss under different energy densities with 40wt.\%TiC powder ratio. Following the increase of the energy density, the wear height loss of the coating was decreased . But the decreasing values were in a relatively small scale, which indicated that the energy density had a nonsignificant effect on the wear height loss, and the trend was consistent with the plot of microhardness change in Fig.11. Combining with Fig.6(c) and Fig.8, it can be concluded that the higher the energy density promoted the stronger the decomposition and re-nucleation of TiC particles, which resulted in the formation of fine $\mathrm{TiC}$ particles. The fine $\mathrm{TiC}$ particles were more stable during wear process and difficult to form wear debris, so an effective reduction of wear height loss can be obtained.

Fig. 15 shows the 3D wear morphologies of coating at different energy densities with $40 \mathrm{wt} \% \mathrm{TiC}$. It can be found that the worn surface of the composite coating had spalling pits (Fig.15(a)), which were caused from the large $\mathrm{TiC}$ hard phase particles peeling off due to incompletion on the decomposition and renucleation process under thelow energy density $\left(52 \mathrm{~J} . \mathrm{mm}^{-2}\right)$. Meanwhile, the TiC hard phases produced micro-cracks and peeled off under the compressive stress and shear forces, which resulted the coating generating spalling pits, and wear form of the worn surface was abrasion wear. The worn surface appeared more wear debris as the increase of the laser energy density (Fig.15(b), Fig.15(c)), and the worn surface became shallower than that of Fig.15(a). Owing to the increase of the laser energy density, the ability of decomposition and re-nucleation of TiC hard phase particles was improved. The coating can obtain finer TiC hard phase particles at high energy densities $\left(58 \mathrm{~J} . \mathrm{mm}^{-2}, 80 \mathrm{~J} \cdot \mathrm{mm}^{-2}\right)$ to improve the wear resistance of the coating, and the wear form of the coating was adhesive wear. When the energy density

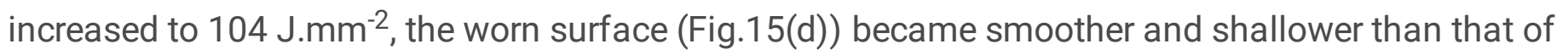
others. This pheonmenon was accomplished by the dissolvement of TiC particles into the Ni based alloy structure, owing to the good wettability among the Ni based alloy, TiC and the AISI 1045 steel substrate.

\subsection{Cofficient of friction}

Fig. 16 shows the average coefficient of friction(COF) of the AISI 1045 steel substrate and the coatings obtained under different conditions following the scratch test shown in table.2. Under the same testing condition, the COF of the AISI 1045 steel substrate was 0.85 , while the lowest COF of the coating was 0.25 (sample 4). It can be seen from the plot with different conditions that the COF of all coatings were significantly lower than the AISI 1045 steel substrate, indicating that the wear resistance of the coating was better than the substrate. Since the micro-hardness of the AISI 1045 steel substrate was lower than the cladding layer, wear debris was easily formed in the scratching test and adhered to each other, which led to the increase of substrate COF than the coatings. The TiC hard phase served as reinforcement particles effectively improve the micro-hardness of the coatings. Along with the increase of energy density, better dissolvement of TiC particles was achieved into the Ni based alloy, which further decreased the COF of coatings.

\section{Conclusions}


Ni35A and Ni35A/TiC composite coatings with high hardness and favorable wear resistance on the AISI 1045 steel substrate were successfully coated by laser cladding process. All the coating had a reliable metallurgical bonding with the AISI 1045 steel substrate.

The effect of laser energy density and TiC powder ratio on the cross-sectional morphology of the coating were analyzed. The TiC powder ratio had a significant effect on the cross-sectional morphology of the coating. Excessive TiC powder ratio was prone to cause peeling off and cracking in the coating.

The main phases of the coating were $\mathrm{Ni}$ and $\mathrm{TiC}$. The decomposition and re-nucleation ability of the TiC were weakened with the increase of $\mathrm{TiC}$ powder ratio or the decrease of laser energy density, which led to the differences of the coating structure under different $\mathrm{TiC}$ powder ratios or different energy densities.

Compared with the AISI 1045 steel substrate, the micro-hardness and wear resistance of the prepared coating had been significantly improved. The coating enhanced the micro-hardness and wear resistance by 5.29 times and 6.26 times, respectively.

Due to the decomposition and re-nucleation effect, the TiC particles were dissolved into the Ni based alloy structure, which improved the wear resistance and reduced the coefficient of friction effectively. The wear form was mainly adhesive wear when changing the TiC powder ratios in different levels. While when the energy densities were adjusted, there was also abrasion wear involved.

\section{Declarations}

Funding: This study was supported by the National Natural Science Foundation of China (No.51575110).

Conflicts of interest: The authors declare no conflict of interests.

Availability of data and material: All related data and materials are available in the manuscript text

Code availability: Not applicable

Authors' contribution: Hao Zhang: Methodology, Investigation, Formal analysis, Writing-original draft. Guofu Lian: Formal analysis, Writing-original draft, Writing-review \& editing, Funding acquisition. Qiang Cao: Investigation, Formal analysis. Yingjun Pan: Formal analysis, Writing-original draft, Writing-review \& editing, Supervision. Yang Zhang: Formal analysis, Writing-original draft, Writing-review \& editing.

\section{References}

[1] A.A. Siddiqui, A.K. Dubey, Recent trends in laser cladding and surface alloying, Opt. Laser Technol.134 (2021) 106619.

[2] D. Deschuyteneer, F. Petit, M. Gonon, F. Cambier, Processing and characterization of laser clad $\mathrm{NiCrBSi}$ /WC composite coatings - Influence of microstructure on hardness and wear, Surf. Coat. Technol. 
283 (2015) 162-171.

[3] Q. Chai, C. Fang, J. Hu, Y. Xing, D. Huang, Cellular automaton model for the simulation of laser cladding profile of metal alloys, Mater. Des. 195 (2020) 109033.

[4] J. Cheng, B. Sun, Y. Ge, X. Hu, L. Zhang, X. Liang, X. Zhang, Effect of B/Si ratio on structure and properties of high-entropy glassy Fe25Co25Ni25(BxSi1-x)25 coating prepared by laser cladding, Surf. Coat. Technol. 402 (2020) 126320.

[5] J. Ning, D.E. Sievers, H. Garmestani, S.Y. Liang, Analytical modeling of in-situ deformation of part and substrate in laser cladding additive manufacturing of Inconel 625, J. Manuf. Process. 49 (2020) 135-140.

[6] K. Xiang, L.-Y. Chen, L. Chai, N. Guo, H. Wang, Microstructural characteristics and properties of CoCrFeNiNbx high-entropy alloy coatings on pure titanium substrate by pulsed laser cladding, Appl. Surf. Sci. 517 (2020) 146214.

[7] A. Khorram, A. Davoodi Jamaloei, A. Jafari, M. Paidar, X. Cao, Microstructural evolution of laser-clad $75 \mathrm{Cr} 3 \mathrm{C} 2+25(80 \mathrm{Ni20Cr})$ powder on Inconel 718 superalloy, J. Mater. Process. Technol. 284 (2020) 116735.

[8] F. Zhang, Y. Qiu, T. Hu, A.T. Clare, Y. Li, L.-C. Zhang, Microstructures and mechanical behavior of betatype Ti-25V-15Cr-0.2Si titanium alloy coating by laser cladding, Mater.Sci. Eng. A. 796 (2020) 140063.

[9] J. Tian, P. Xu, Q. Liu, Effects of stress-induced solid phase transformations on residual stress in laser cladding a Fe-Mn-Si-Cr-Ni alloy coating, Mater. Des. 193 (2020) 108824.

[10] L. Zhu, S. Wang, H. Pan, C. Yuan, X. Chen, Research on remanufacturing strategy for 45 steel gear using H13 steel powder based on laser cladding technology, J. Manuf. Process. 49 (2020) 344-354.

[11] J.M.S.d. Sousa, F. Ratusznei, M. Pereira, R.d.M. Castro, E.I.M. Curi, Abrasion resistance of Ni-Cr-B-Si coating deposited by laser cladding process, Tribol. Int. 143 (2020) 106002.

[12] Y.L. Zhang, J. Li, Y.Y. Zhang, D.N. Kang, Evolution in microstructure and high-temperature oxidation behaviors of the laser-cladding coatings with the Si addition contents, J. Alloys Compd. 827 (2020) 154131.

[13] M.R. Fernández, A. García, J.M. Cuetos, R. González, A. Noriega, M. Cadenas, Effect of actual WC content on the reciprocating wear of a laser cladding NiCrBSi alloy reinforced with WC, Wear. 324-325 (2015) 80-89.

[14] I. Hulka, D. Utu, V.A. Serban, P. Negrea, F. Lukáč, T. Chráska, Effect of Ti addition on microstructure and corrosion properties of laser cladded WC-Co/NiCrBSi(Ti) coatings, Appl. Surf. Sci. 504 (2020) 144349. 
[15] K. Kılıçay, S. Buytoz, M. Ulutan, Microstructural and tribological properties of induction cladded NiCrBSi /WC composite coatings, Surf. Coat. Technol. 397 (2020) 125974.

[16] Y. Zhao, T. Yu, L. Chen, Y. Chen, C. Guan, J. Sun, Microstructure and wear resistance behavior of TiC-B4C-reinforced composite coating, Ceram. Int. 46 (2020) 25136-25148.

[17] Q.-Y. Wang, R. Pei, S. Liu, S.-L. Wang, L.-J. Dong, L.-J. Zhou, Y.-C. Xi, S.-L. Bai, Microstructure and corrosion behavior of different clad zones in multi-track Ni-based laser-clad coating, Surf. Coat. Technol. $402(2020) 126310$.

[18] A. Gowtham, G. Chaitanya, J.K. Katiyar, A. Chandak, T.V.K. Gupta, Experimental investigations on laser cladding of NiCrBSi +WC coating on SS410, Mater. Today: Proc. 27 (2020) 1984-1989.

[19] D. Davoodi, R. Miri, A.H. Emami, M. Tayebi, S. Salahshour, The effect of NiO catalyst on reduction, synthesis and binder content of TiC-Ni nanocomposite, Int. J. Refract. Met. Hard Mater. 88 (2020) 105175.

[20] J. He, G. Zheng, F. Guo, G. Fu, C. Li, H. Zhao, Y. Qin, Y. Jiang, F. Yin, Microstructure and tribological properties of in-situ synthesized TiC reinforced reactive plasma sprayed Co-based coatings, Mater. Chem. Phys. 248 (2020) 122913.

[21] Y.-d. Ma, X.-y. Wang, X.-I. Wang, Y. Yang, Y.-h. Cui, W.-w. Sun, In-situ TiC-Ti5Si3-SiC composite coatings prepared by plasma spraying, Surf. Coat. Technol. 404 (2020) 126484.

[22] P.F. Jiang, C.H. Zhang, S. Zhang, J.B. Zhang, J. Chen, Y. Liu, Fabrication and wear behavior of TiC reinforced FeCoCrAlCu-based high entropy alloy coatings by laser surface alloying, Mater. Chem. Phys. 255 (2020) 123571.

[23] L. Hu, S. Li, C. Li, G. Fu, J. He, Y. Dong, Y. Yang, H. Zhao, Y. Qin, F. Yin, Deposition and properties of plasma sprayed NiCrCoMo-TiC composite coatings, Mater. Chem. Phys. 254 (2020) 123502.

[24] S. Saroj, C.K. Sahoo, M. Masanta, Microstructure and mechanical performance of TiC-Inconel825 composite coating deposited on AISI 304 steel by TIG cladding process, J. Mater. Process. Technol. 249 (2017) 490-501.

[25] R. Saeedi, R. Shoja Razavi, S.R. Bakhshi, M. Erfanmanesh, A. Ahmadi Bani, Optimization and characterization of laser cladding of $\mathrm{NiCr}$ and $\mathrm{NiCr}-\mathrm{TiC}$ composite coatings on AISI 420 stainless steel, Ceram. Int. 47 (2021) 4097-4110.

[26] D. Gu, H. Zhang, D. Dai, M. Xia, C. Hong, R. Poprawe, Laser additive manufacturing of nano-TiC reinforced Ni-based nanocomposites with tailored microstructure and performance, Compos.B. Eng. 163 (2019) 585-597. 
[27] G. Muvvala, S. Mullick, A.K. Nath, Development of process maps based on molten pool thermal history during laser cladding of Inconel 718/TiC metal matrix composite coatings, Surf. Coat. Technol. 399 (2020) 126100.

[28] M.-Y. Shen, X.-J. Tian, D. Liu, H.-B. Tang, X. Cheng, Microstructure and fracture behavior of TiC particles reinforced Inconel 625 composites prepared by laser additive manufacturing, J. Alloys Compd. 734 (2018) 188-195.

[29] A. Sahu, A. Raheem, M. Masanta, C.K. Sahoo, On the constancy in wear characteristic of large area TiC-Ni coating developed by overlapping of TIG arc scanning, Tribol. Int. 151 (2020) 106501.

[30] Q. Shi, D. Gu, M. Xia, S. Cao, T. Rong, Effects of laser processing parameters on thermal behavior and melting/solidification mechanism during selective laser melting of $\mathrm{TiC} /$ Inconel 718 composites, Opt. Laser Technol. 84 (2016) 9-22.

[31] C. Hong, D. Gu, D. Dai, M. Alkhayat, W. Urban, P. Yuan, S. Cao, A. Gasser, A. Weisheit, I. Kelbassa, M. Zhong, R. Poprawe, Laser additive manufacturing of ultrafine TiC particle reinforced Inconel 625 based composite parts: Tailored microstructures and enhanced performance, Mater.Sci. Eng. A. 635 (2015) 118128.

[32] H.C. Man, S. Zhang, F.T. Cheng, T.M. Yue, In situ synthesis of TiC reinforced surface MMC on Al6061 by laser surface alloying, Scripta Mater. 46 (2002) 229-234.

[33] C.L. Wu, S. Zhang, C.H. Zhang, H. Zhang, S.Y. Dong, Phase evolution and properties in laser surface alloying of FeCoCrAlCuNix high-entropy alloy on copper substrate, Surf. Coat. Technol. 315 (2017) 368376.

[34] C.K. Sahoo, M. Masanta, Microstructure and mechanical properties of TiC-Ni coating on AISI304 steel produced by TIG cladding process, J. Mater. Process. Technol. 240 (2017) 126-137.

[35] Y.F. Liu, J.S. Mu, X.Y. Xu, S.Z. Yang, Microstructure and dry-sliding wear properties of TiC-reinforced composite coating prepared by plasma-transferred arc weld-surfacing process, Mater.Sci. Eng. A 458 (2007) 366-370.

[36] H.F. El-Labban, E.R.I. Mahmoud, A. Algahtani, Microstructure, Wear, and Corrosion Characteristics of TiC-Laser Surface Cladding on Low-Carbon Steel, Metall. Mater. Trans. B. 47 (2016) 974-982.

[37] G. Muvvala, D. Patra Karmakar, A.K. Nath, In-process detection of microstructural changes in laser cladding of in-situ Inconel 718/TiC metal matrix composite coating, J. Alloys Compd. 740 (2018) 545558.

[38] C.A. León-Patiño, M. Braulio-Sánchez, E.A. Aguilar-Reyes, E. Bedolla-Becerril, Microstructure, mechanical and thermal properties of Ni matrix composites reinforced with high-volume TiC, J. Alloys Compd. 792 (2019) 1102-1111. 
[39] A. Shahroozi, A. Afsari, B. Khakan, A.R. Khalifeh, Microstructure and mechanical properties investigation of stellite 6 and Stellite 6/TiC coating on ASTM A105 steel produced by TIG welding process, Surf. Coat. Technol. 350 (2018) 648-658.

[40] A. Pakdel, A. Witecka, G. Rydzek, D.N. Awang Shri, A comprehensive microstructural analysis of AlWC micro- and nano-composites prepared by spark plasma sintering, Mater. Des. 119 (2017) 225-234.

[41] X. Sun, J. Huang, J. Yang, S. Chen, Microstructure evolution and mechanical properties of in-situ bimodal TiC-Fe coatings prepared by reactive plasma spraying, Ceram. Int 45 (2019) 5848-5857.

\section{Figures}
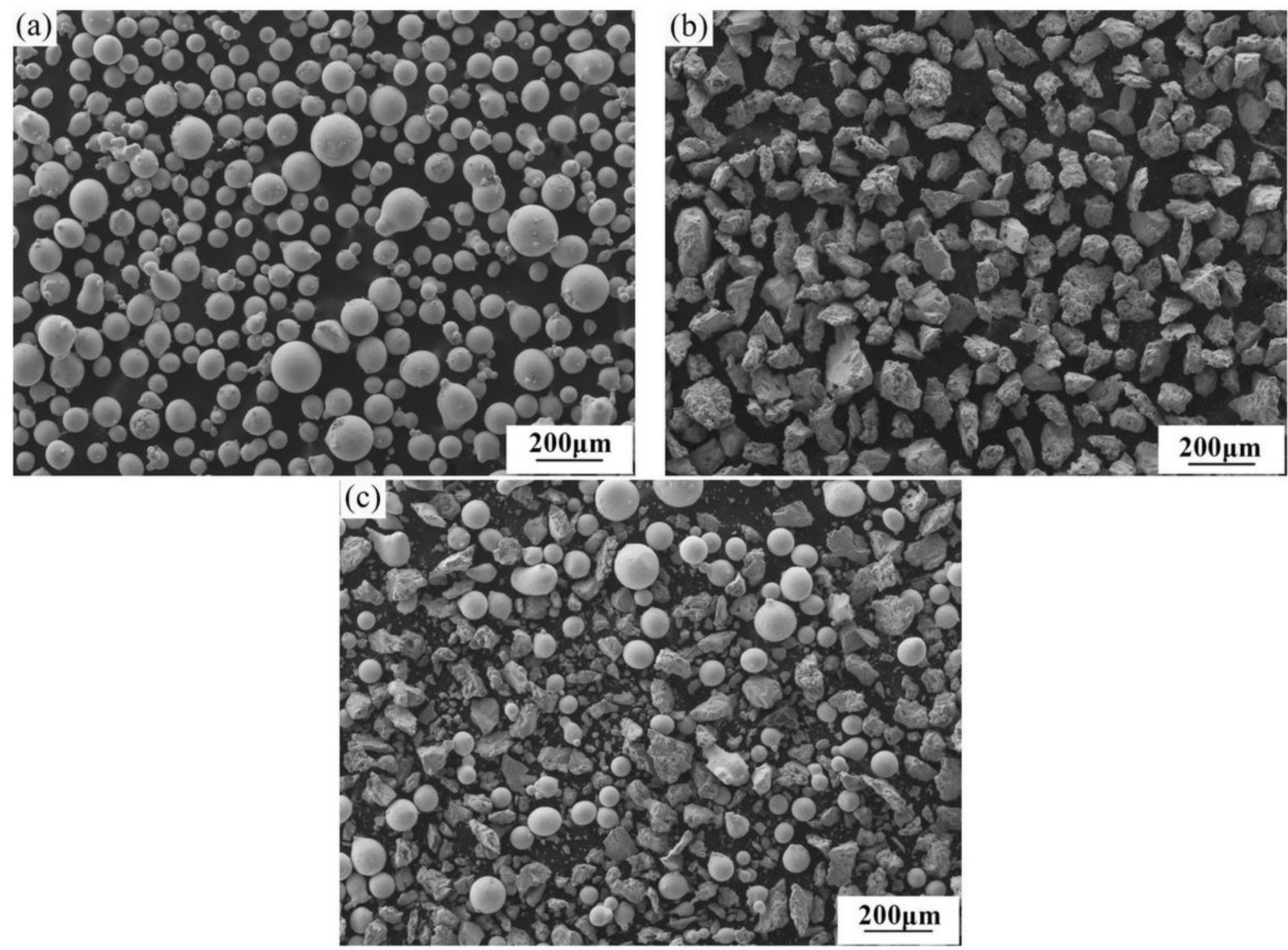

\section{Figure 1}

SEM images of (a) Ni35A powder; (b) TiC powder; (c) TiC/Ni35A powder mixture after ball milling. 

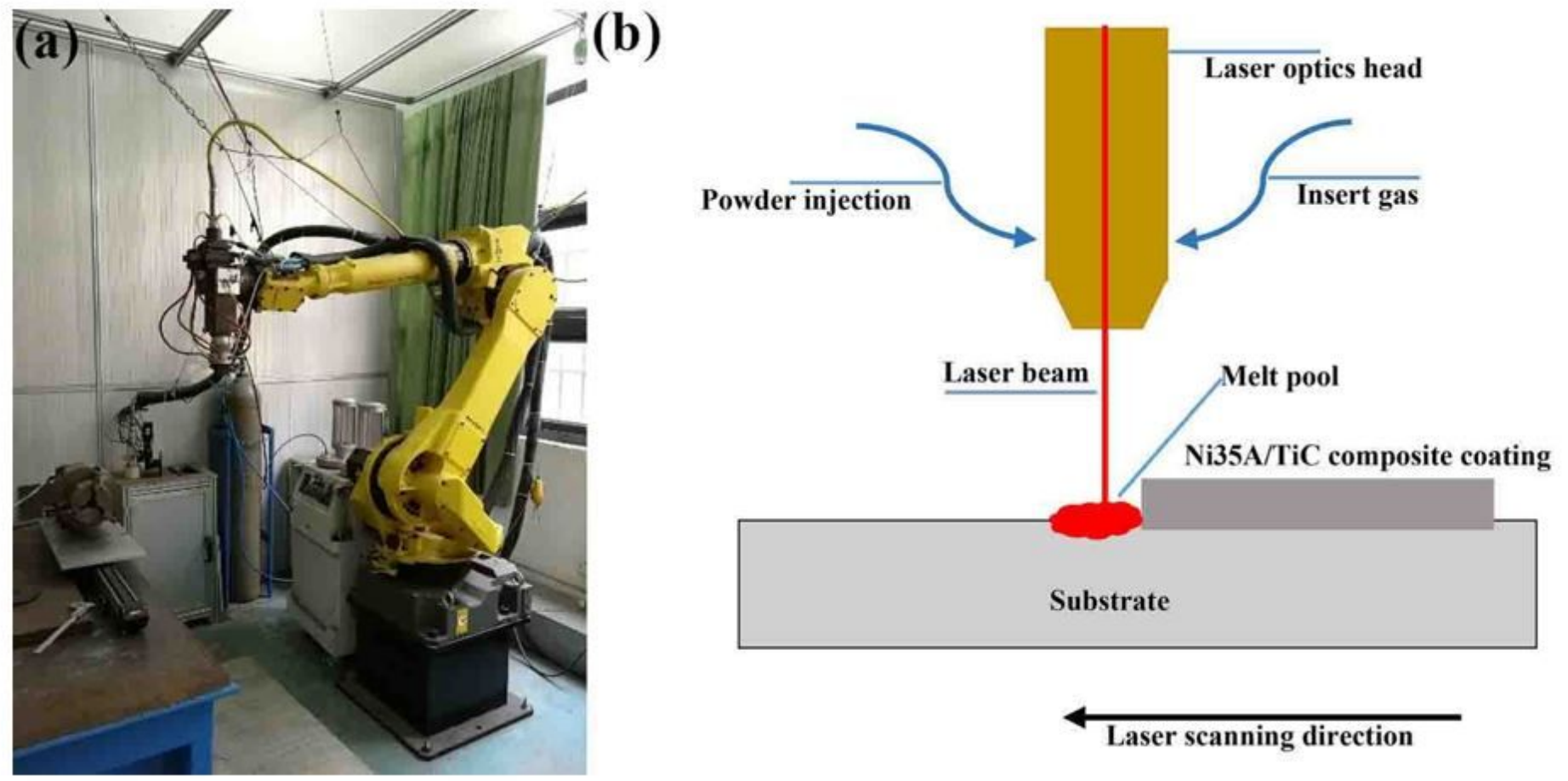

Figure 2

(a) Laser cladding system; (b) Schematic diagram of laser cladding process. 

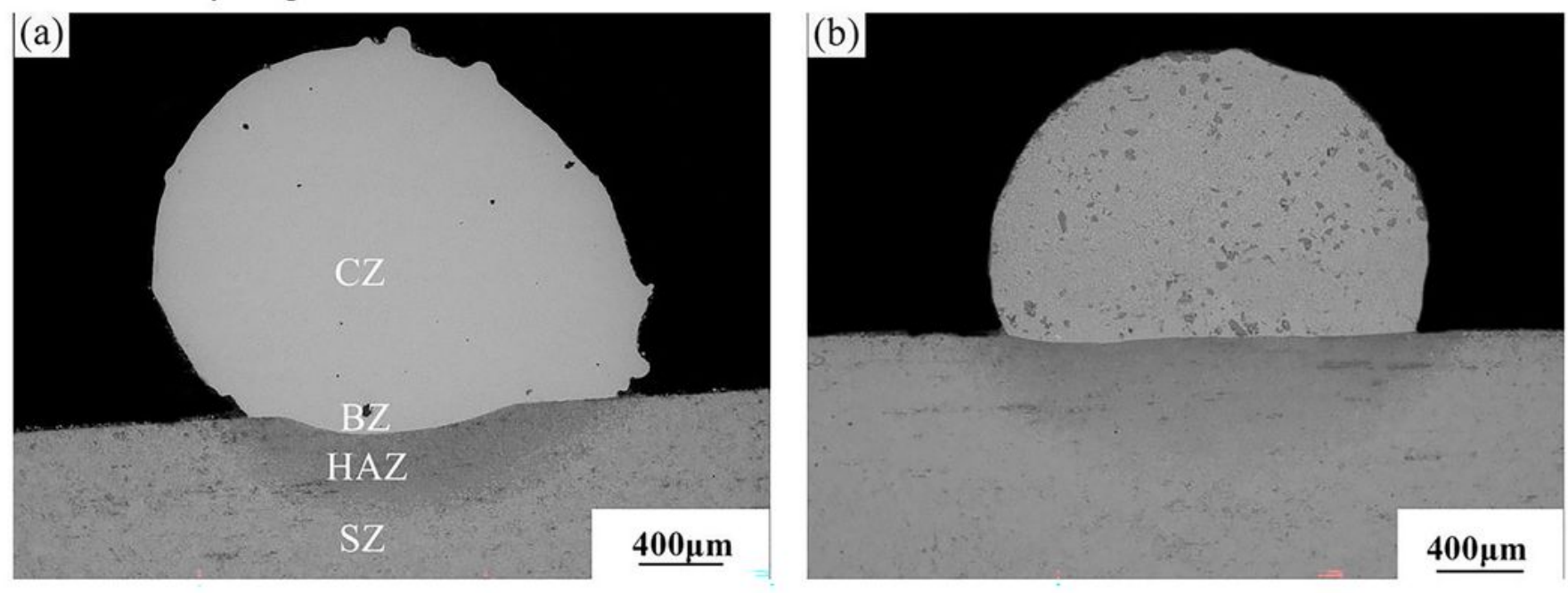

\section{(c)}
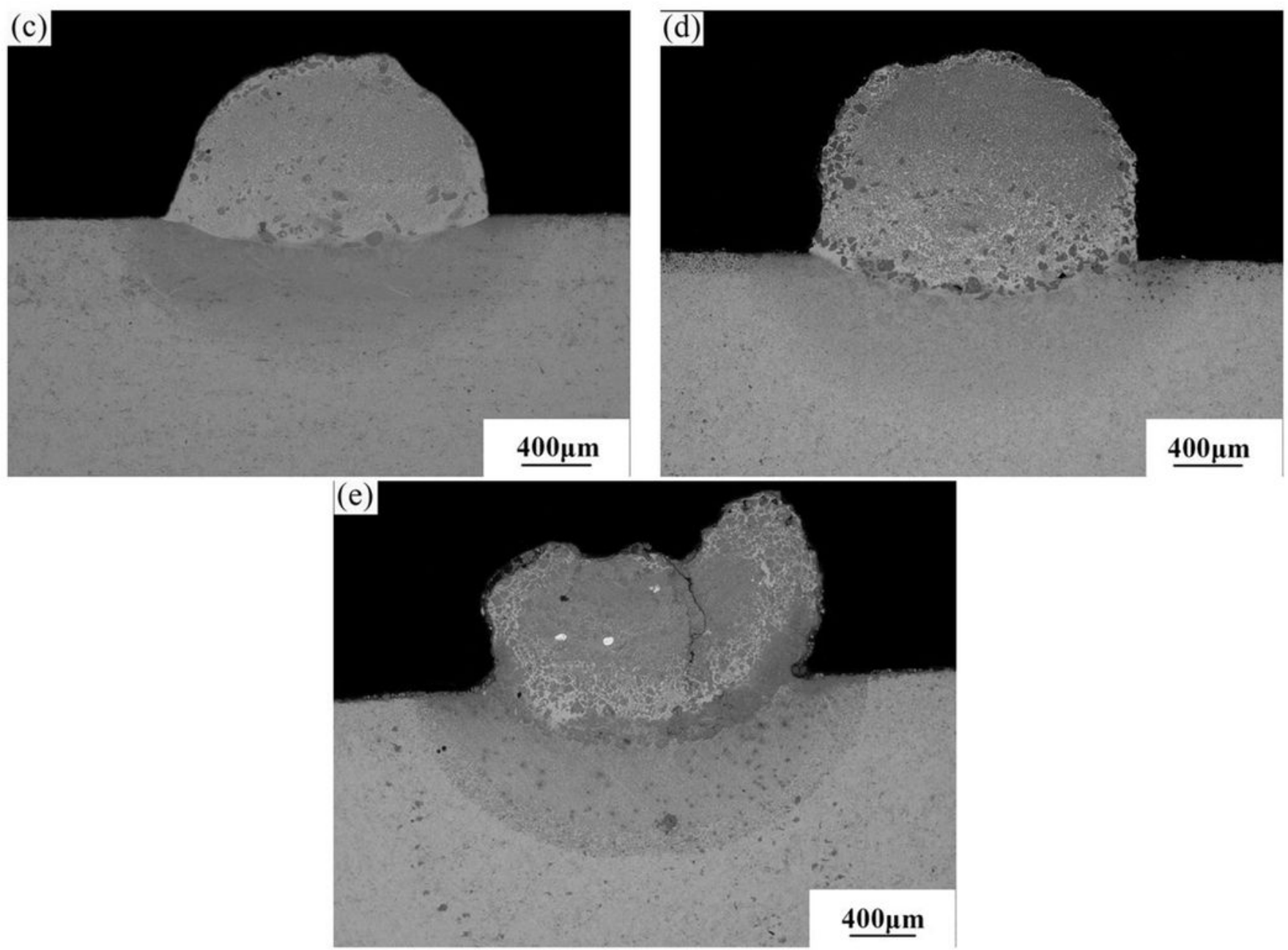

Figure 3

Cross-section SEM images of the coatings deposited with $69 \mathrm{~J} . \mathrm{mm}-2$ energy density and different TiC powder ratios (a) 0; (b) 20wt.\%; (c) 40wt.\% ;(d) 60wt.\%; (e) 80wt.\%. 

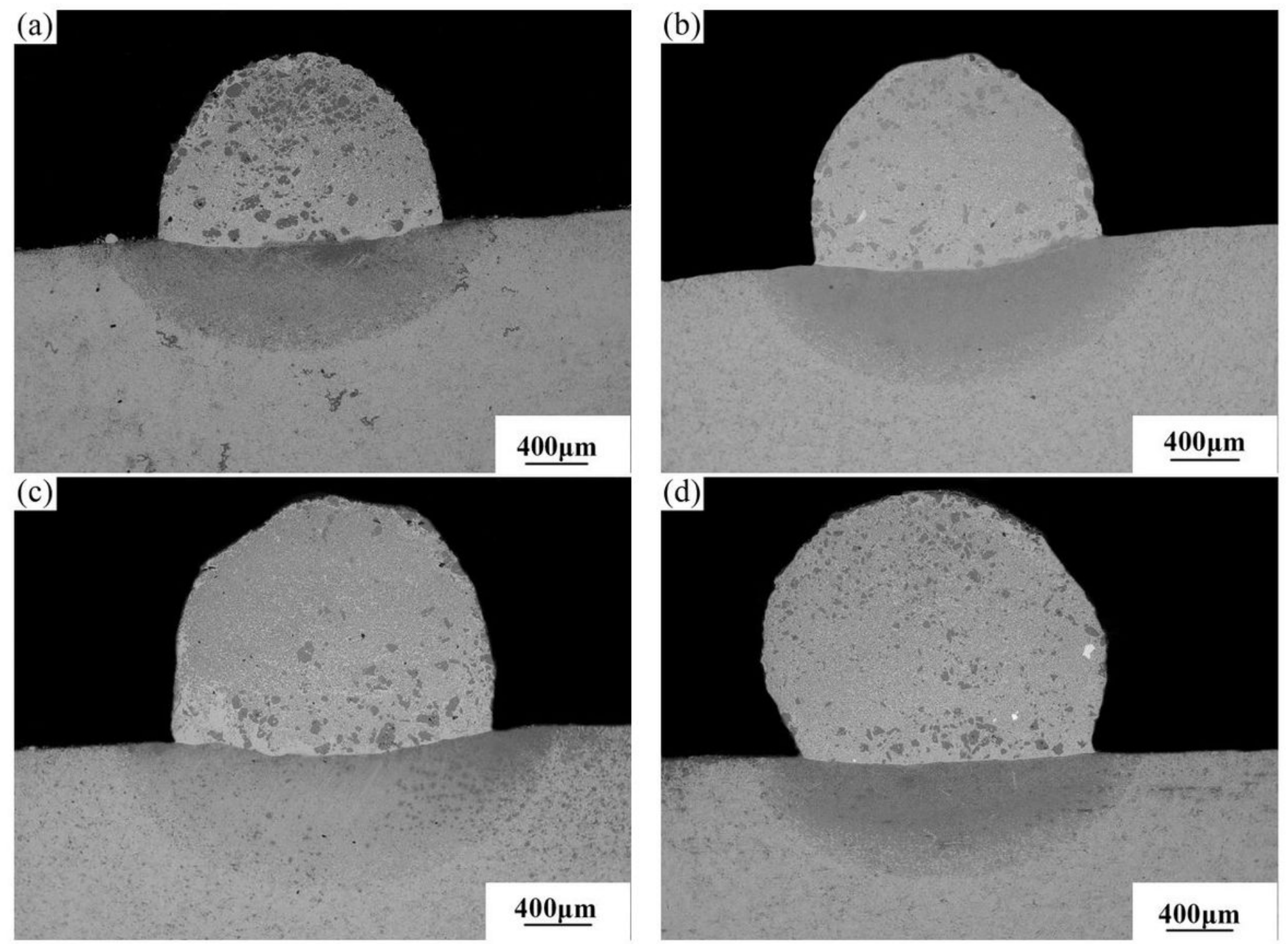

Figure 4

Cross-section SEM images of the coating deposited with $40 \mathrm{wt} \%$ TiC and different energy densities (a)52 J.mm-2 (b) 58 J.mm-2 (c) 80 J.mm-2 (d) 104 J.mm-2. 


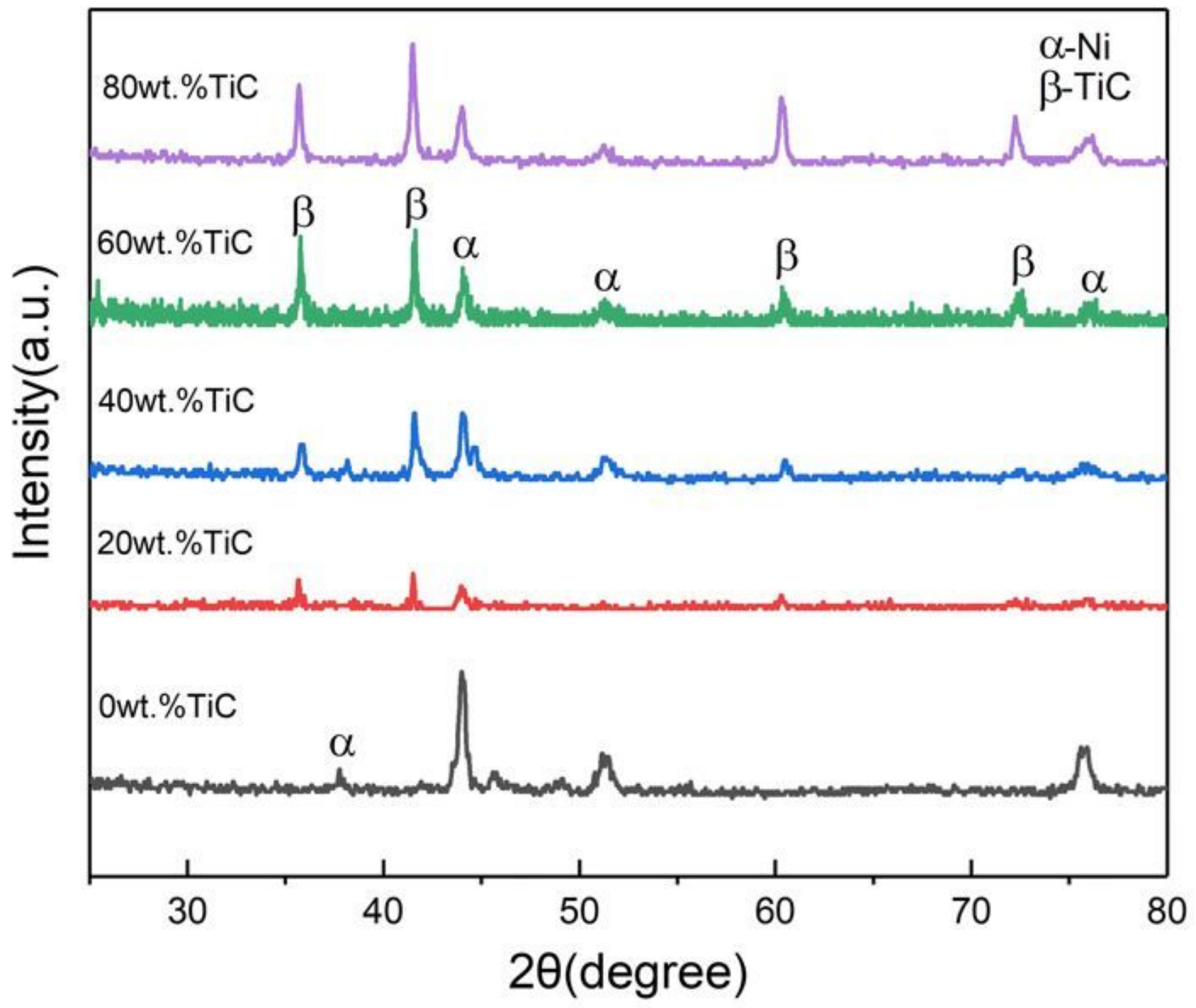

Figure 5

XRD patterns of TiC-Ni35A coating on the AISI 1045 steel with different TiC powder ratios $(0,20,40,60$, $80 \mathrm{wt} . \%)$ by laser cladding. 

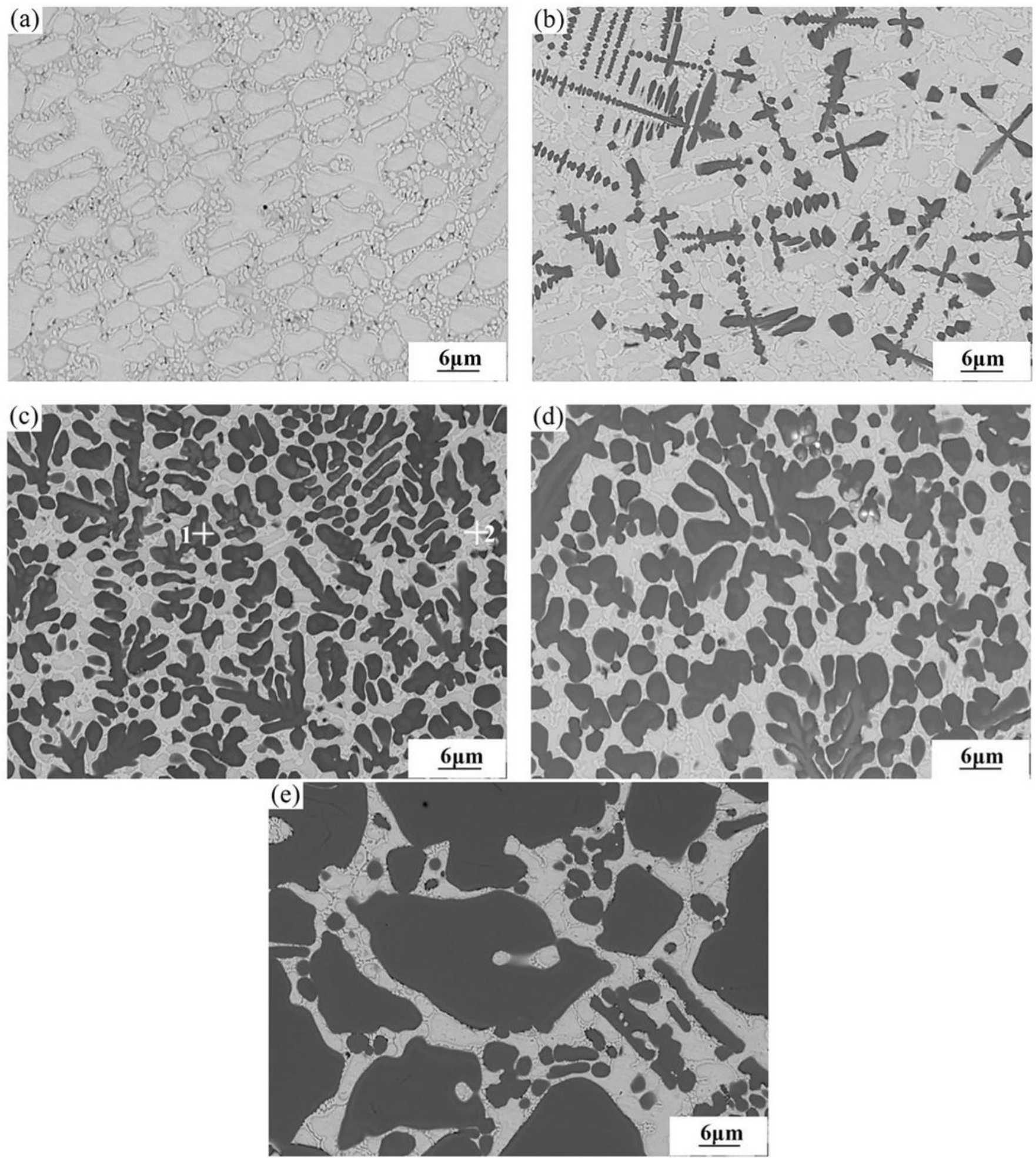

Figure 6

XRD patterns of TiC-Ni35A coating on the AISI 1045 steel with different TiC powder ratios $(0,20,40,60$, $80 \mathrm{wt} . \%)$ by laser cladding. 


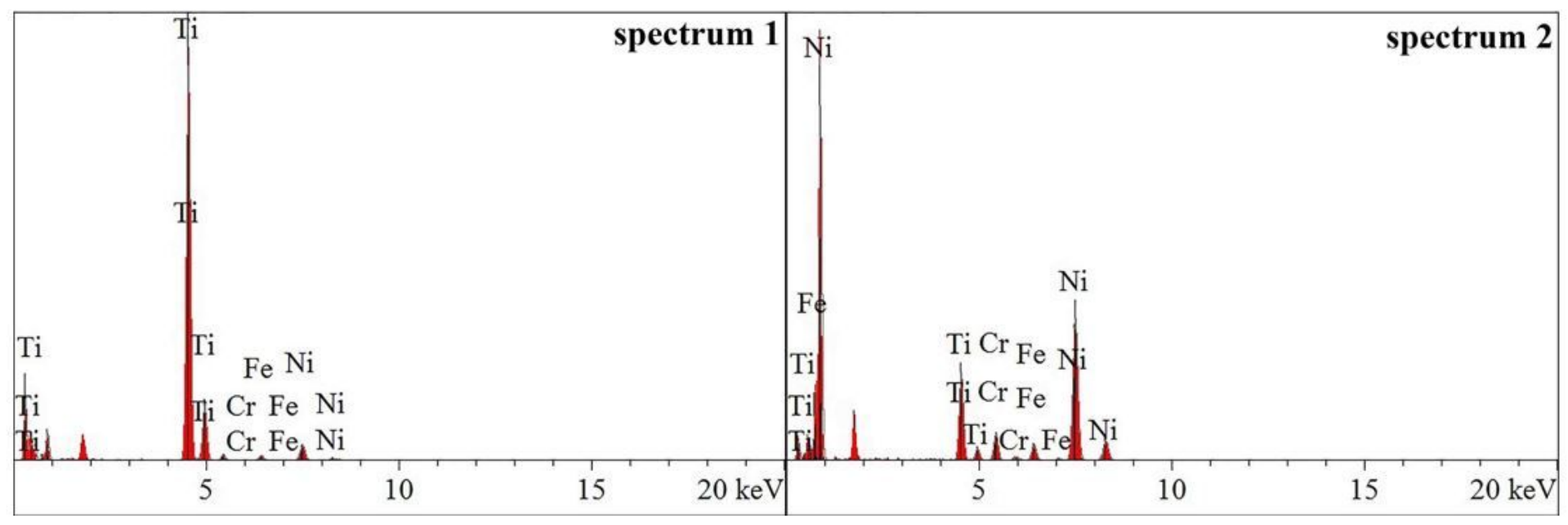

Figure 7

EDS elemental analysis of the dark reinforced particle (mark \#1) and light region of the coating (mark \#2) in Fig.6(c).
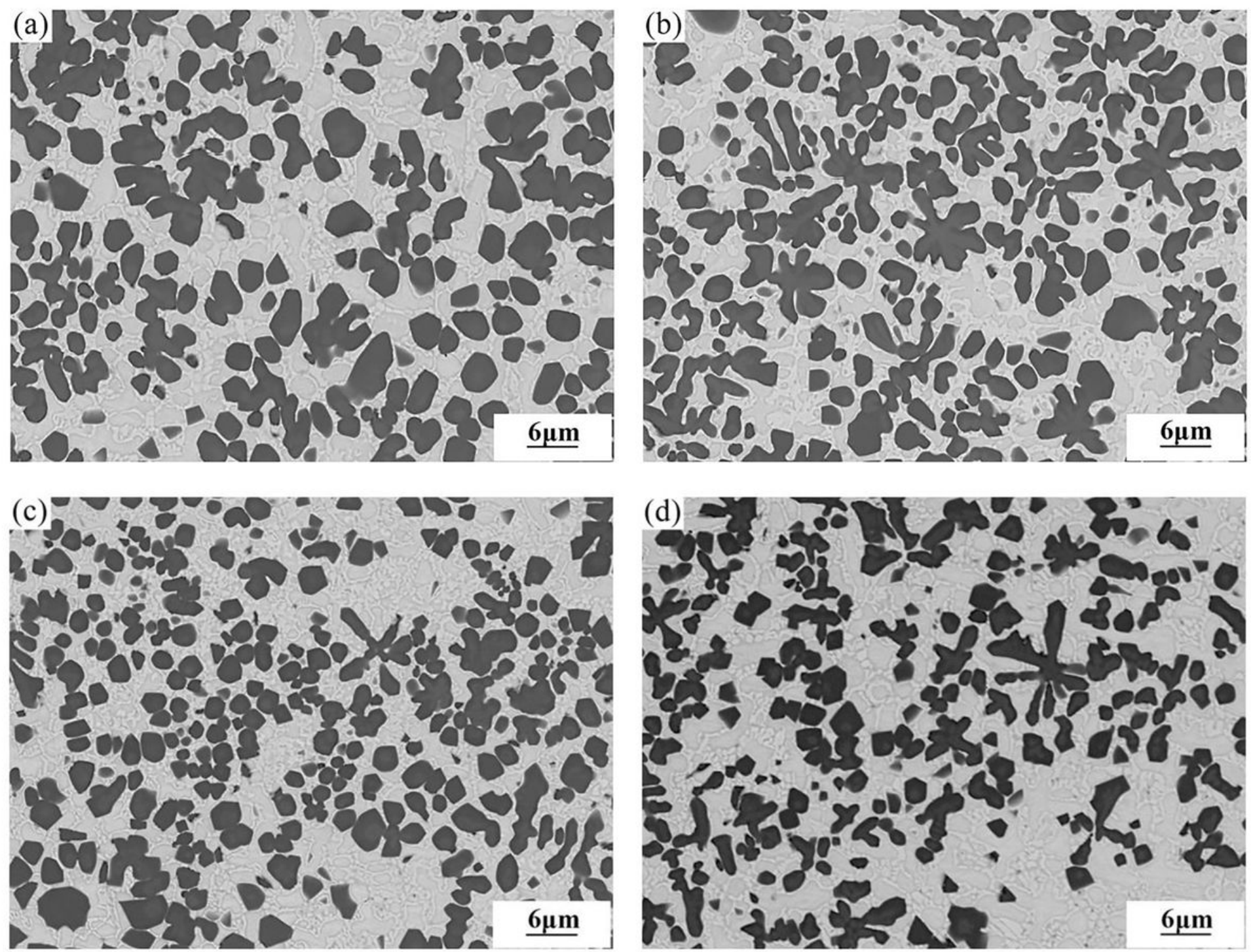


\section{Figure 8}

High magnified SEM images of the cross-section of the coating produced with $40 \mathrm{wt}$. \% $\mathrm{TiC}$ and different laser energy densities (a) 52J.mm-2 (b)58J.mm-2 (c) 80J.mm-2 (d) 104J.mm-2.
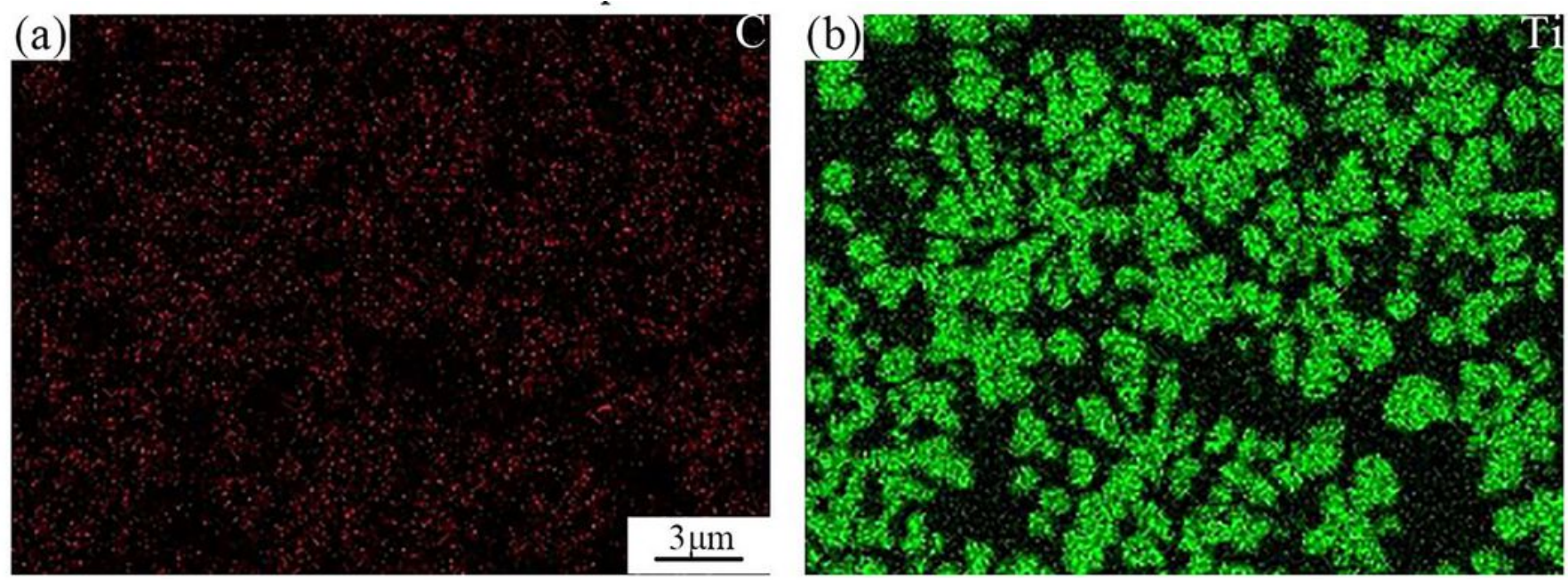

\section{(c)}

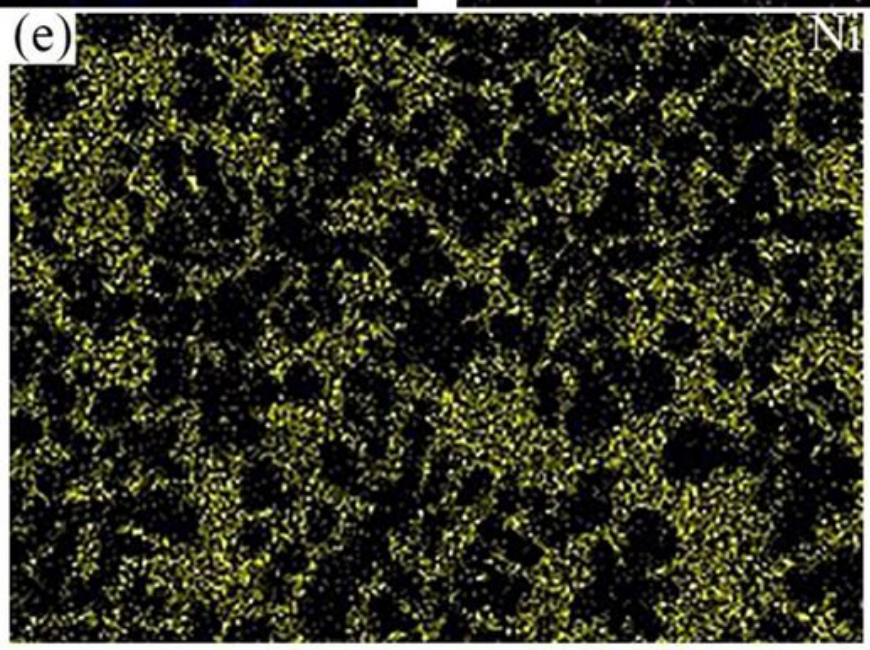

\section{Figure 9}

Mapping EDS analysis of the Fig.8(b). 


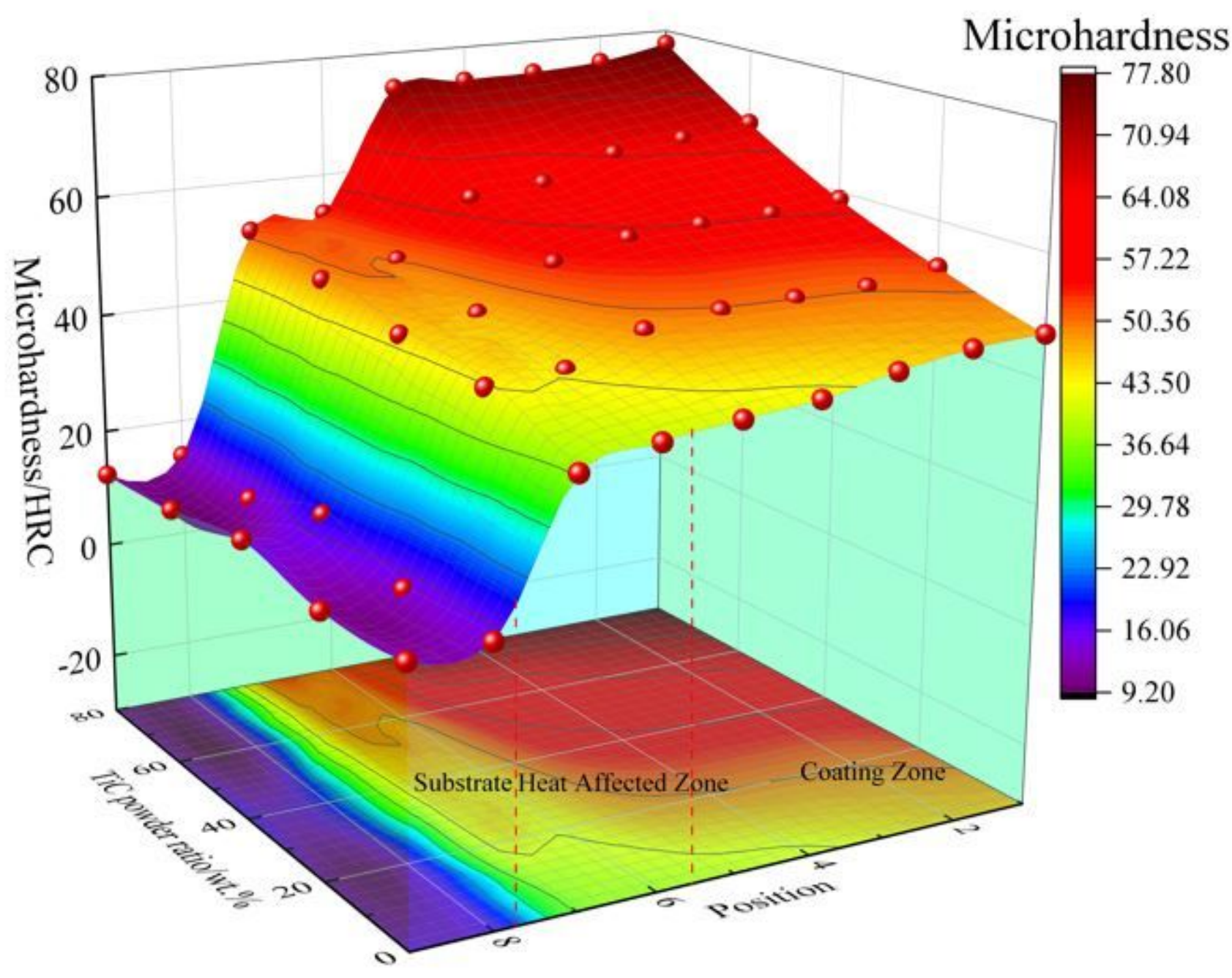

Figure 10

Influence of $\mathrm{TiC}$ powder ratio(wt.\%) on the microhardness and its distribution in coatings. 


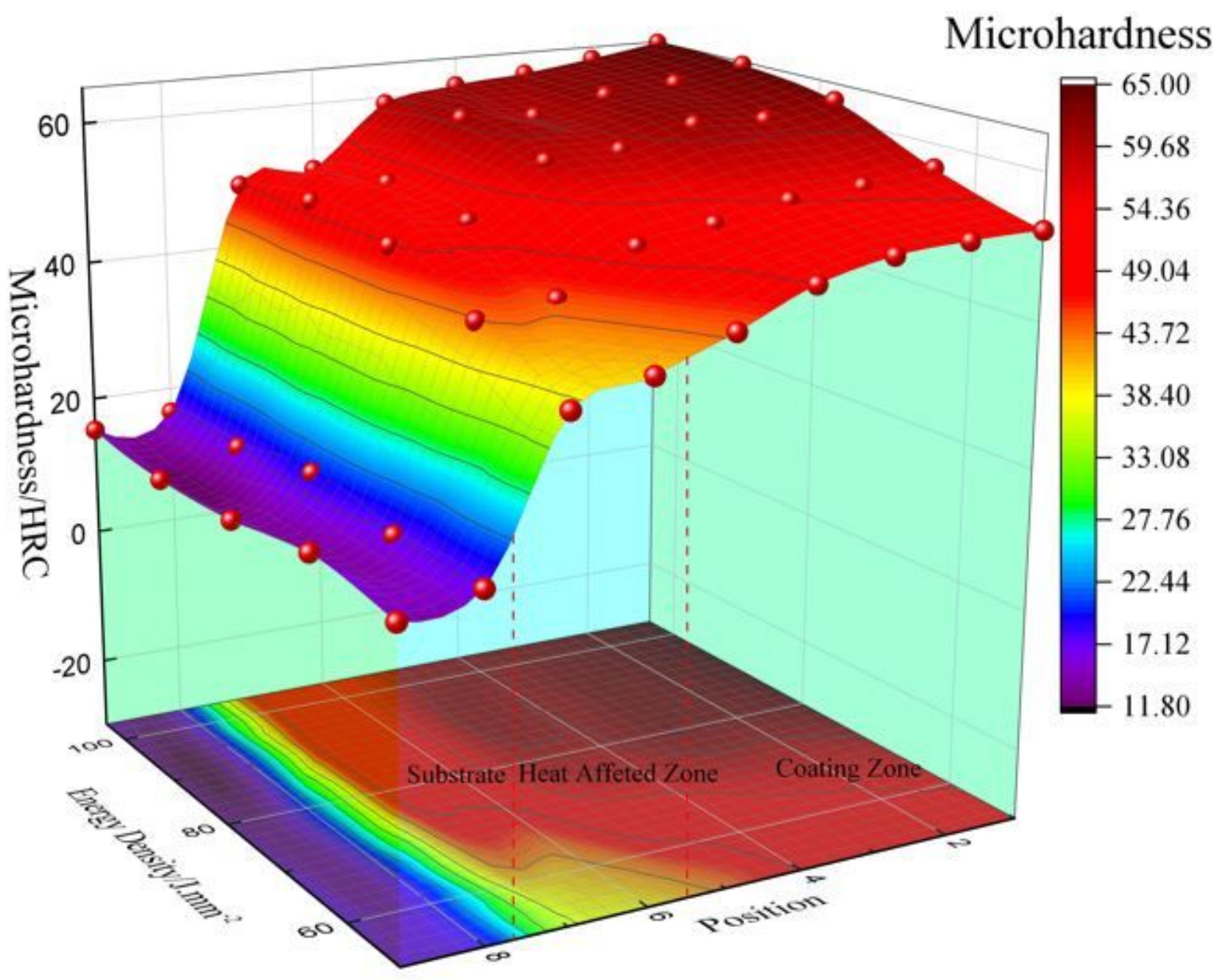

Figure 11

Influence of energy density on the microhardness and its distribution in coatings. 


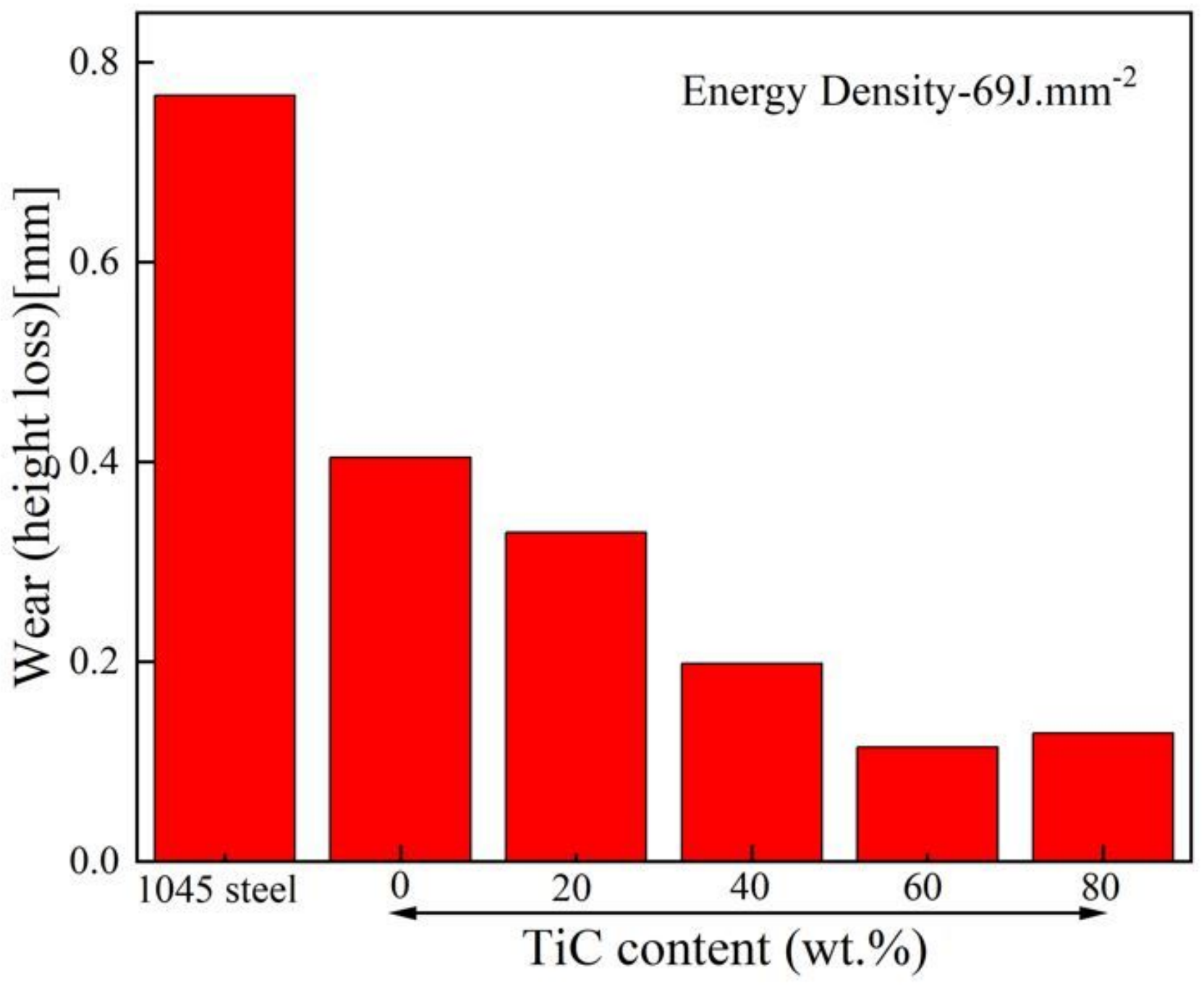

Figure 12

Comparative wear height loss in 1045 steel and samples produced by different TiC powder ratios with 69 J.mm-2 energy density. 

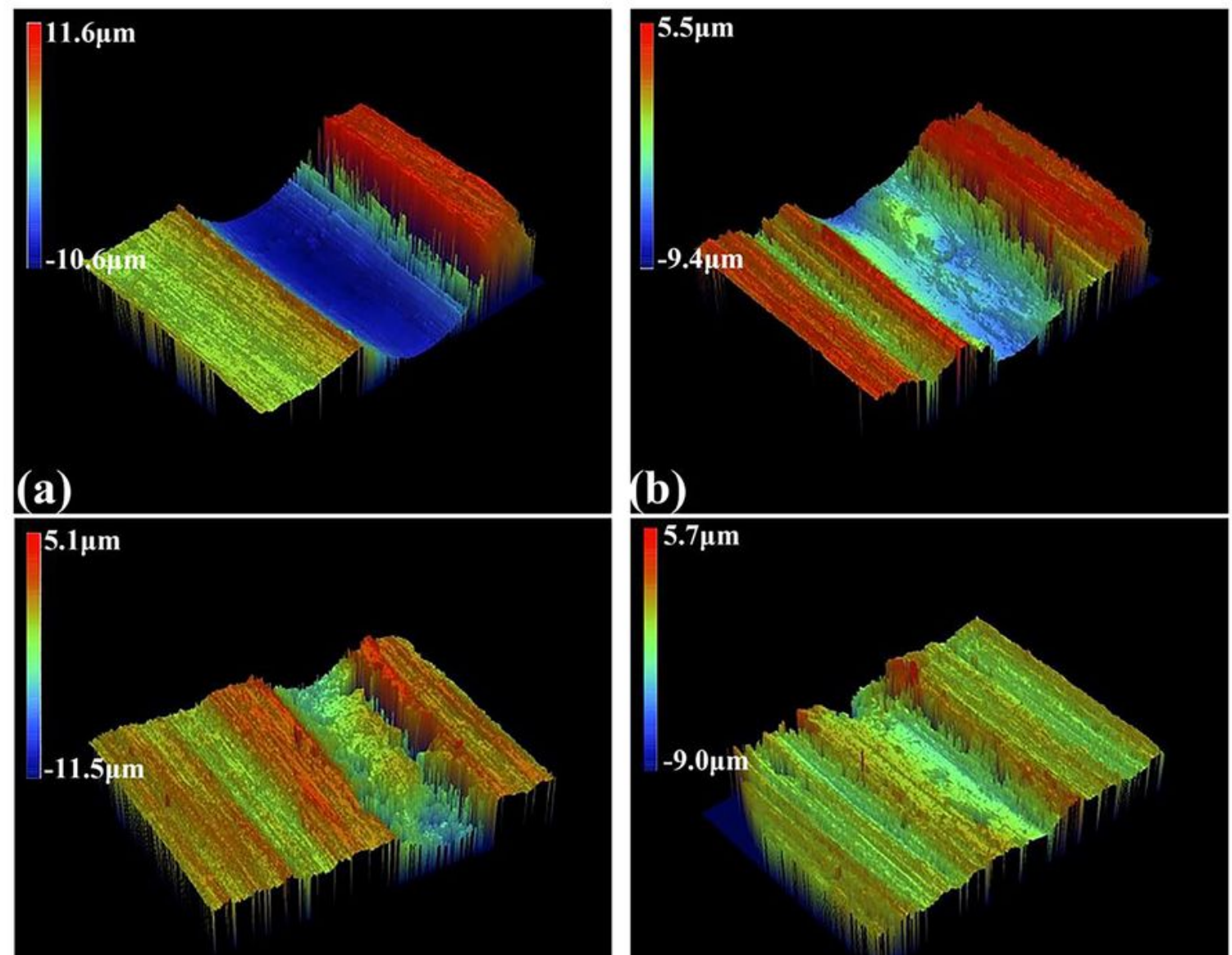

(c)
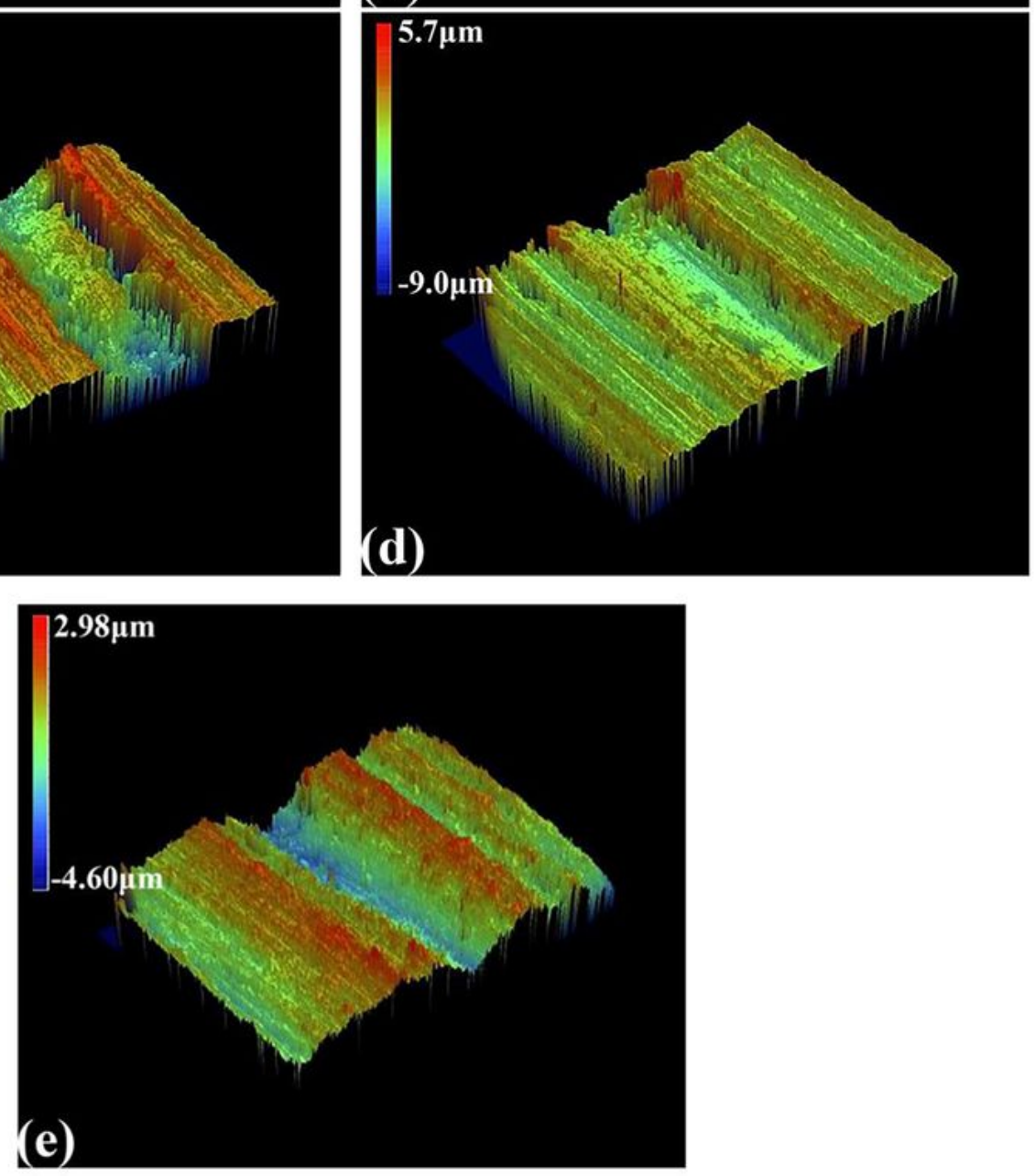

\section{Figure 13}

3D wear morphologies of coating produced with $69 \mathrm{~J} . \mathrm{mm}-2$ energy density and different TiC powder ratios (a)0, (b)20wt.\%, (c)40wt.\%, (d)60wt.\% and (e) 80wt.\%. 


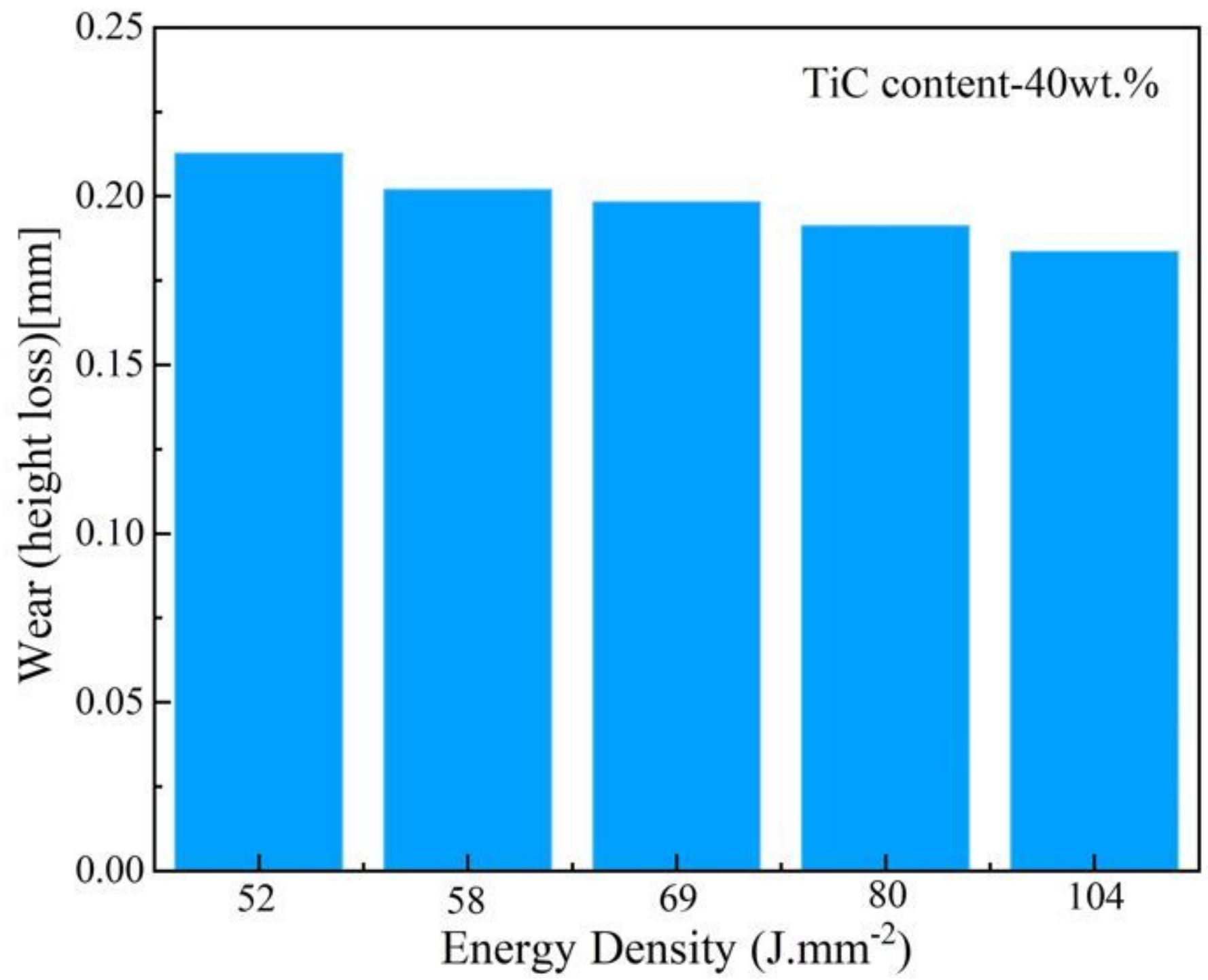

Figure 14

Comparative wear height loss in samples produced by $40 \mathrm{wt} . \% \mathrm{TiC}$ powder ratio and different energy densities. 

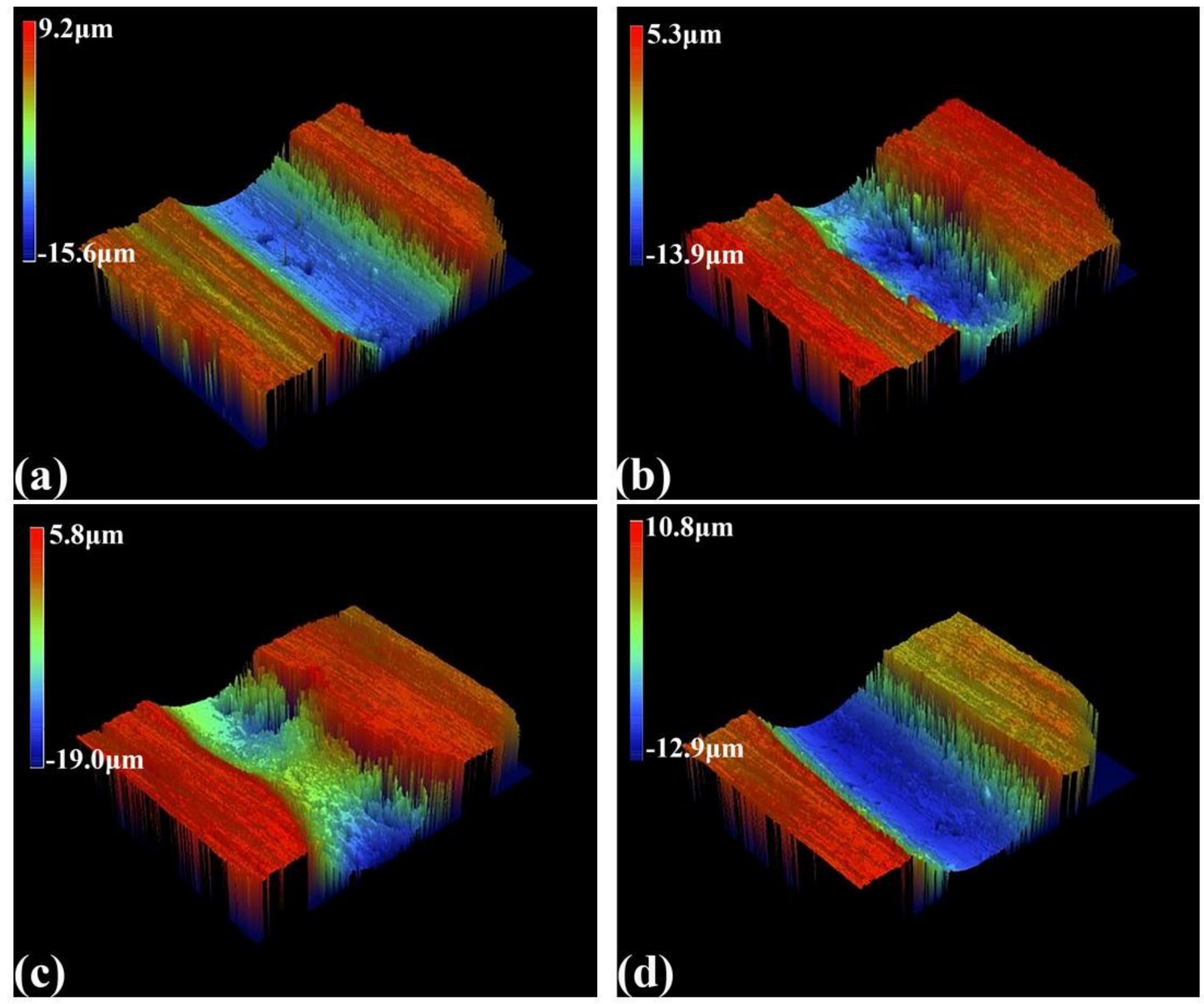

\section{Figure 15}

3D wear morphologies of coating produced with $40 \mathrm{wt} \% \mathrm{TiC}$ powder ratio and different energy densities (a) 52 J.mm-2, (b) 58 J.mm-2, (c) 80 J.mm-2 and (d) 104 J.mm-2. 


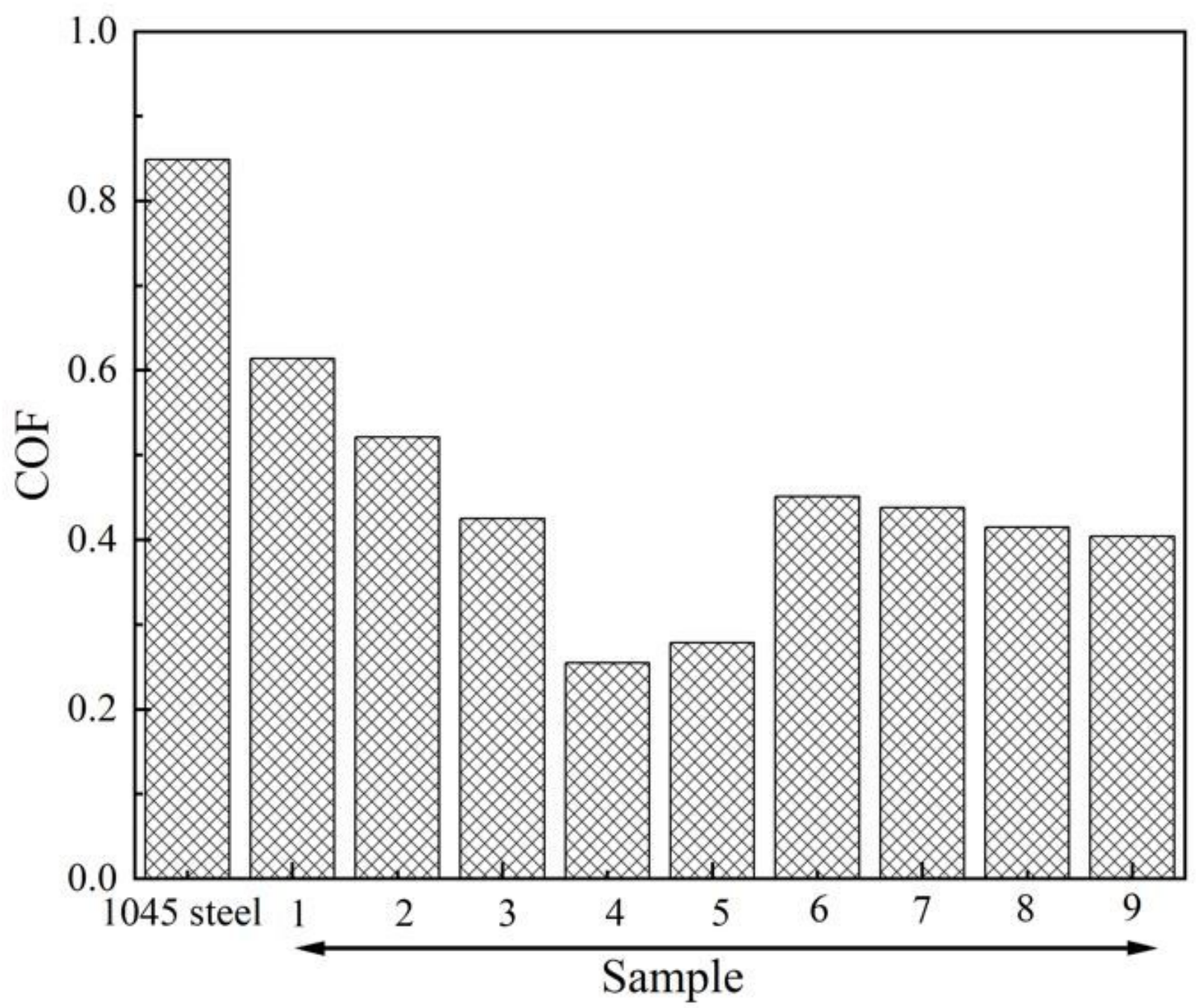

Figure 16

Comparative coefficient of friction in 1045 steel and samples coated under different settings. 